\title{
The Effect of Morphology of Activated Electrodes on Their Electrochemical Activity 3
}

\author{
Konstantin I. Popov, ${ }^{1,2}$ Predrag M. Živković, ${ }^{2} \quad 4$ \\ and Nebojša D. Nikolić ${ }^{1}$ \\ ${ }^{1}$ ICTM-Institute of Electrochemistry, University of Belgrade, \\ Njegoševa 12, Belgrade, Serbia 7 \\ ${ }^{2}$ Faculty of Technology and Metallurgy, University of Belgrade, 8 \\ Karnegijeva 4, Belgrade, Serbia
}

I. INTRODUCTION

The noble metals or their oxides are the most convenient substrates 11 for most electrochemical reactions taking place in fuel cells or in 12 industrial electrolysis, for example. Because of this, the "activated" 13 electrodes are introduced, consisting of a conducting, inert sup- 14 port coated with a thin layer of electrocatalyst. In this way, not 15 only the chemical nature of the electrode can be modified but also 16 its morphology and structure in dependence on the procedure of 17 preparation. ${ }^{1}$

The transformation of the properties of an electrode surface 19 from those of an inexpensive inert substrate to those of an active one 20 with a small quantity of an expensive active metal is one of the most 21 important problems of electrocatalysis today. Numerous papers 22 substantiate that different catalyst for different electrochemical 23

S.S. Djokić (ed.), Electrodeposition: Theory and Practice,

Modern Aspects of Electrochemistry 48, DOI 10.1007/978-1-4419-5589-0_4,

(C) Springer Science+Business Media, LLC 2010 
reactions have been developed by placing appropriate active 24 nanoparticles, usually of noble metals, on a carbon support, for 25 example, for the electrochemical oxidation of methanol, ${ }^{2}$ the elec- 26 trochemical reduction of oxygen, ${ }^{3}$ the electrochemical oxidation 27 of oxalic acid, ${ }^{4}$ etc. Naturally, the catalyst can also be placed on 28 metal or carbon substrate by electrodeposition. Formerly, metallic 29 supports were the only substrates used in cathodic formation of 30 electrodeposits. Nowadays, various exotic conductive materials are 31 also experimented. ${ }^{5}$

According to Bockris et al., ${ }^{6}$ the cell voltage of a self-driving 33 cell, $U_{\mathrm{s}}$, is given by

$$
U_{\mathrm{s}}=U_{\mathrm{e}}-\Delta U
$$

and the cell voltage of a driven cell, $U_{\mathrm{d}}$, by

$$
U_{\mathrm{d}}=U_{\mathrm{e}}+\Delta U
$$

The power $P_{\mathrm{s}}$, which can be obtained from self-driving cells, 36 like batteries and fuel cells, is

$$
P_{\mathrm{s}}=\left(U_{\mathrm{e}}-\Delta U\right) I
$$

and the power $P_{\mathrm{d}}$, required for driving the cells in, for example, elec- 38 trowining of metals, is

$$
P_{\mathrm{d}}=\left(U_{\mathrm{e}}+\Delta U\right) I
$$

where

$$
\Delta U=\eta_{\mathrm{a}}+\eta_{\mathrm{c}}+I R
$$

and $U_{\mathrm{e}}$ is the equilibrium cell potential, $\eta_{\mathrm{a}}$ and $\eta_{\mathrm{c}}$ the absolute values 41 of overpotentials of both electrodes, and $I$ and $R$ are the cell current 42 and cell Ohmic resistance, respectively.

The overpotential $\eta$ in mixed activation-diffusion control is 44 given by

$$
\eta=\eta_{\mathrm{ac}}+\eta_{\mathrm{d}}
$$

where $\eta_{\mathrm{ac}}$ and $\eta_{\mathrm{d}}$ are the activation and diffusion overpotential, re- 46 spectively. It follows from (3) to (6) that $\Delta U, P_{\mathrm{S}}$, and $P_{\mathrm{d}}$ depend on 47 both activation and diffusion overpotentials and on Ohmic voltage 48 drop in the cell.

The activation overpotential mainly depends on the kinetic pa- 50 rameters of processes under consideration on the given substrate 51 


\section{The Effect of Morphology of Activated Electrodes}

and on the actual current density. The diffusion overpotential mainly 52 depends on the actual current density to the limiting current density 53 ratio, and the Ohmic voltage drop depends on the current in the cell, 54 the composition of the solution, and geometry of the system. 55

Obviously, $\Delta U$ represents the losses of energy, and making $U 56$ near $U_{\mathrm{e}}$, or $\Delta U$ as low as possible, is the crucial problem of the 57 applied electrochemistry.

There are two basic problems in activation of inert substrates 59 by electrodeposition: first, the effect of the structure of the active 60 surface film on the transformation of electrode from inert to active 61 one $^{7}$ and second, effect of the surface morphology on the polariza- 62 tion characteristics of activated electrodes. ${ }^{8,9}$ Obviously, in the last 63 case, the nature of the initial substrate is not important. The analysis 64 of both of them is the aim of this chapter. It will be performed for 65 the cathodic reactions. Obviously, the corresponding analysis for the 66 anodic processes can be performed in the similar way. 67

Metallic electrodeposits allow surfaces with a variety of mor- 68 phological characteristics to be obtained. The granular electrode- 69 posits represent the model of the partially covered inert substrate. ${ }^{7} 70$ Deposits with a high roughness factor and good mechanical resis- 71 tance are of particular interest. These two important aspects are usu- 72 ally mutually exclusive, as high values of the roughness factor are 73 mainly obtained through growth of dendrites that have low mechan- 74 ical resistance ${ }^{10}$ Hence, such coverings are unsuitable as electrocat- 75 alysts. On the other hand, the dendritic deposits are the best-known 76 form of the disperse deposits, ${ }^{11-13}$ being the most suitable for the- 77 oretical analysis. The dendrites are used here as an example of the 78 disperse deposit characterized with large roughness factor during the 79 analysis of the polarization behavior of activated electrodes. This is 80 because this chapter is written in order to explain the polarization 81 behavior of activated electrodes, not to give some concrete technical 82 solutions.

\section{MICRO- AND MACROELECTRODES}

In all actual electrochemical converters, the electrodes are three- 85 dimensional, porous structures, the pores of which contain the cata- 86 lyst material to and from which electric charge transfer occurs. ${ }^{14} 87$

The electrodic catalyst consists of active nanoparticles. The dis- 88 tribution of the active material on the surface inside the pores is very 89 
important for obtaining the necessary activity of the solid phase. 90 This is because the activity of a porous structure depends on both 91 mass transfer through it and on the electrochemical properties of the 92 surface. $^{7}$

Mass transfer in a porous structure strongly depends on macro- 94 geometric parameters, but the electrochemical properties of the 95 surface of the solid phase depend on the mutual relation of the ac- 96 tive particles on it, being independent of the macrogeometry of the 97 system.

In spite of some specific characteristics of nanoparticles, this 99 can also be treated as the case of an inert substrate modified with 100 active grains in general. Naturally, for the sake of simplicity, this 101 analysis can be performed for planar electrodes.

According to Scharifker and Hills, ${ }^{15}$ in systems where the 103 charge transfer is fast, the rates of growth of nuclei are well de- 104 scribed in terms of control by mass transfer of the electrodepositing 105 ions to the growth centers.

During this stage of the growth of the deposit, the nuclei develop 107 diffusion zones around themselves, and as these zones overlap, the 108 hemispherical mass transfer gives way to linear mass transfer to an 109 effectively planar surface. The current then falls, and the transient 110 approaches that corresponding to the total electrode surface.

Similarly, it was shown by Gilleadi ${ }^{16}$ that the development of 112 a diffusion field near the surface of an ensemble of microelectrodes 113 occurs in the four successive steps, assuming total diffusion con- 114 trol of the process. The ensemble of microelectrodes consists of mi- 115 croelectrodes placed on the inert surface at distances between their 116 centers larger than their diameter. The first, planar diffusion to the 117 microelectrodes; the second, spherical diffusion with no overlap; the 118 third, spherical diffusion with substantial overlap; and finally, total 119 overlap, equivalent to planar diffusion to the whole surface.

Stonehart and Wheeler ${ }^{17}$ and Popov et al. ${ }^{7}$ correlated the 121 current densities on the microelectrodes, taking into account the 122 change of concentration around them, with the current density on 123 the macroelectrode. This is because the charge transfer occurs on the 124 microelectrodes, while the mass-transfer limitations are related to 125 the diffusion layer of the macroelectrode. In this chapter, the model 126 of the surface of Popov et al. ${ }^{7}$ will be used to describe the polar- 127 ization behavior of previously activated inert macroelectrode with 128 active microelectrodes. 
The Effect of Morphology of Activated Electrodes

The cathodic polarization curve equation for flat or large 130 spherical electrode is given by

$$
j=\frac{j_{0}\left(f_{\mathrm{c}}-f_{\mathrm{a}}\right)}{1+\frac{j_{0} f_{\mathrm{c}}}{j_{\mathrm{L}}}},
$$

where $j, j_{0}$, and $j_{\mathrm{L}}$ are the current density, exchange current density, 132 and limiting diffusion current density, respectively, and

$$
\begin{aligned}
& f_{\mathrm{c}}=10^{\frac{\eta}{b_{\mathrm{c}}}}, \\
& f_{\mathrm{a}}=10^{-\frac{\eta}{b_{\mathrm{a}}}},
\end{aligned}
$$

where $b_{\mathrm{c}}$ and $b_{\mathrm{a}}$ are the cathodic and anodic Tafel slopes and $\eta$ is the 134 overpotential. Equation (7) is modified for use in electrodeposition 135 of metals by taking cathodic current density and overpotential as 136 positive. Derivation of (7) is performed under assumption that the 137 concentration dependence of $j_{0}$ can be neglected. ${ }^{12,18,19}$

It is known ${ }^{12}$ that electrochemical processes on microelectrodes 139 in bulk solution can be under activation control at overpotentials, 140 which correspond to the limiting diffusion current density plateau of 141 the macroelectrode. The cathodic limiting diffusion current density, 142 $j_{\mathrm{L}, \mathrm{Sp}}$, for steady-state spherical diffusion is given by:

$$
j_{\mathrm{L}, \mathrm{Sp}}=\frac{n F D C_{0}}{r}
$$

and for steady-state linear diffusion, $j_{\mathrm{L}}$, by:

$$
j_{\mathrm{L}}=\frac{n F D C_{0}}{\delta}
$$

where $n$ is the number of transferred electrons, $F$ the Faraday con- 145 stant, $D$ and $C_{0}$ the diffusion coefficient and bulk concentration of 146 the depositing ion, respectively, $r$ the radius of the spherical micro- 147 electrode, and $\delta$ is the diffusion layer thickness of the macroelec- 148 trode. It follows from (10) and (11) that:

$$
\frac{j_{\mathrm{L}, \mathrm{Sp}}}{j_{\mathrm{L}}}=\frac{\delta}{r} .
$$




\section{K.I. Popov et al.}

An electrode around which the hydrodynamic diffusion layer 150 can be established, being considerably lower than dimensions of 151 it, could be considered as a macroelectrode. An electrode, mainly 152 spherical, whose diffusion layer is equal to the radius of it, satisfying 153

$$
\delta \gg r
$$

can be considered as a microelectrode. ${ }^{11}$

According to (7) for

$$
f_{\mathrm{c}} \gg f_{\mathrm{a}} \text { and } \frac{j_{0} f_{\mathrm{c}}}{j_{\mathrm{L}}} \gg 1
$$

the cathodic process on the macroelectrode enters full diffusion con- 156 trol, i.e.,

$$
j \cong j_{\mathrm{L}}
$$

Simultaneously, the cathodic current density on the hemispher- 158 ical microelectrode, $j_{\text {Sp }}$, is given by:

$$
j_{\mathrm{Sp}}=\frac{j_{0}\left(f_{\mathrm{c}}-f_{\mathrm{a}}\right)}{1+\frac{j_{0} f_{\mathrm{c}}}{j_{\mathrm{L}, \mathrm{Sp}}}}
$$

or, because of (12)

$$
j_{\mathrm{Sp}}=\frac{j_{0}\left(f_{\mathrm{c}}-f_{\mathrm{a}}\right)}{1+\left(\frac{j_{0}}{j_{\mathrm{L}}}\right)\left(\frac{r}{\delta}\right) f_{\mathrm{c}}}
$$

and, if condition (14) is also valid, but

$$
\frac{r}{\delta} \rightarrow 0 .
$$

Equation (17) can be rewritten in the form

$$
j=j_{0} f_{\mathrm{c}} \text {. }
$$

This means that the process on the microelectrode in the bulk 163 solution can be under complete activation control at the same 164 overpotential at which the same process on the macroelectrode 165 is simultaneously under full diffusion control. 
The Effect of Morphology of Activated Electrodes

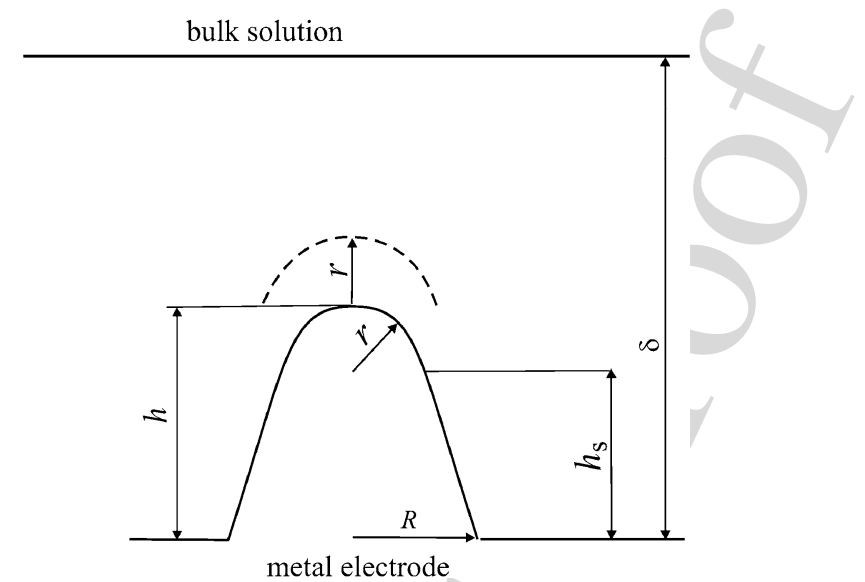

Figure 1. Model of a paraboloidal surface protrusion; $h$ is the height of the protrusion relative to the flat portion of the surface, $h_{\mathrm{S}}$ is the corresponding local side elongation, $r$ is the radius of the protrusion tip, $R$ is the radius of the protrusion base, $\delta$ is the thickness of the diffusion layer and $\delta \gg h$. Reprinted from ref. ${ }^{7}$ with permission of Elsevier.

Naturally, the microelectrodes can be placed on the macroelec- 167 trodes inside their diffusion layers. Let us consider the model of 168 surface irregularities shown in Fig. 1. The electrode surface irregu- 169 larities are buried deep in the diffusion layer, which is characterized 170 by a steady linear diffusion to the flat portion of the surface. ${ }^{7,20}$

At the side of an irregularity, the limiting diffusion current den- 172 sity, $j_{\mathrm{L}, \mathrm{S}}$, is given as:

$$
j_{\mathrm{L}, \mathrm{S}}=\frac{n F D C_{0}}{\delta-h_{\mathrm{S}}}=j_{\mathrm{L}} \frac{\delta}{\delta-h_{\mathrm{s}}} .
$$

Obviously, this is valid if the protrusion height does not affect 174 the outer limit of the diffusion layer, and that a possible lateral dif- 175 fusion flux supplying the reacting ions can be neglected. At the tip 176 of an irregularity, the lateral flux cannot be neglected and the situa- 177 tion can be approximated by assuming a spherical diffusion current 178 density, $j_{\mathrm{L}, \text { tip }}$, given by: ${ }^{20}$

$$
j_{\mathrm{L}, \mathrm{tip}}=\frac{n F D C^{*}}{r}
$$


K.I. Popov et al.

where $C^{*}$ is the concentration of the diffusing species at a distance $r \quad 180$ from the tip, assuming that around the tip a spherical diffusion layer 181 having a thickness equal to the radius of the protrusion tip is formed. 182 If deposition to the macroelectrode is under full diffusion control, 183 the distribution of the concentration $C$ inside the linear diffusion 184 layer is given by: ${ }^{12}$

$$
C=C_{0} \frac{h}{\delta},
$$

where $0 \leq h \leq \delta$. Hence,

$$
C^{*}=C_{0} \frac{h+r}{\delta}
$$

and

$$
j_{\mathrm{L}, \mathrm{tip}}=j_{\mathrm{L}}\left(1+\frac{h}{r}\right)
$$

because of (11), (21), and (23).

The tip radius of the paraboloidal protrusion is given by ${ }^{11-13}$

$$
r=\frac{R^{2}}{2 h}
$$

and substitution of $r$ from (25) in (24) gives

or

where

$$
j_{\mathrm{L}, \mathrm{tip}}=j_{\mathrm{L}}\left(1+2 k^{2}\right)
$$

If $h=R, k=1$, hence for a hemispherical protrusion,

$$
j_{\mathrm{L}, \text { tip }}=3 j_{\mathrm{L}}
$$

If $h \ll R, k \rightarrow 0$,

$$
j_{\mathrm{L}, \mathrm{tip}} \rightarrow j_{\mathrm{L}}
$$

and if $R \ll h, k \rightarrow \infty$ and

$$
j_{\mathrm{L}, \mathrm{tip}} \rightarrow \infty
$$


The Effect of Morphology of Activated Electrodes

Substitution of $j_{\mathrm{L} \text {,tip }}$ from (27) instead of $j_{\mathrm{L}}$ in (7) and further 196 rearranging give:

$$
j_{\text {tip }}=\frac{j_{0}\left(f_{\mathrm{c}}-f_{\mathrm{a}}\right)}{1+\left(\frac{j_{0}}{j_{\mathrm{L}}} \cdot \frac{1}{1+2 k^{2}} f_{\mathrm{c}}\right)}
$$

The current density on the tip of a protrusion, $j_{\text {tip }}$, is determined by 198 $k$, hence by the shape of the protrusion. If $k \rightarrow 0, j_{\text {tip }} \rightarrow j$ (see (7)) 199 and if $k \rightarrow \infty, j_{\text {tip }} \rightarrow j_{0}\left(f_{\mathrm{c}}-f_{\mathrm{a}}\right) \gg j$. The electrochemical pro- 200 cess on the tip of a sharp needle-like protrusion can be under pure 201 activation control outside the diffusion layer of the macroelectrode. 202 Inside it, the process on the tip of a protrusion is under mixed con- 203 trol, regardless it is under complete diffusion control on the flat part 204 of the electrode for $k \rightarrow 0$. If $k=1$, hence for hemispherical protru- 205 sion, $j_{\text {tip }}$ will be somewhat larger than $j$, but the kind of control will 206 not be changed. It is important to note that the current density to the 207 tip of hemispherical protrusion does not depend on the size of it if 208 $k=1$. This makes a substantional difference between spherical mi- 209 croelectrodes in bulk solution and microelectrodes inside diffusion 210 layer of the macroelectrode. ${ }^{16}$ In the first case, the limiting diffusion 211 current density depends strongly on the radius of the microelectrode. 212

Taking into account that the exchange current density depends 213 on the concentration of reacting ion, it follows that the growth of 214 dendrites $^{12,21,22}$ inside the diffusion layer of the macroelectrode is 215 in fact under mixed activation-diffusion control. Hence, it can be 216 expected that the process on the microelectrodes placed on the sur- 217 face of the inert macroelectrode can be under mixed control. This 218 is because the charge transfer occurs on the microelectrodes, while 219 the mass-transfer limitations are related to the diffusion layer of the 220 macroelectrode.

\section{INERT MACROELECTRODE PARTIALLY 222 COVERED WITH HEMISPHERICAL ACTIVE 223 MICROELECTRODES 224}

1. Mathematical Model 225

The use of microelectrodes is impractical, but the use of ensembles 226 of microelectrodes can be a real option. The ensemble of microelec- 227 trodes consists of microelectrodes placed on the inert surface at dis- 228 tances between their centers larger than their diameter. 


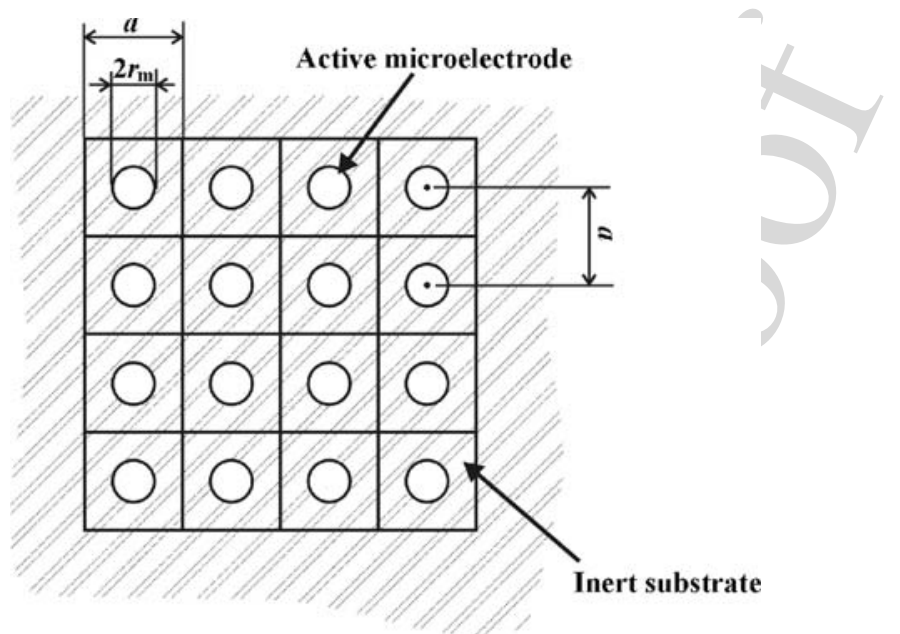

Figure 2. A schematic presentation of the top view of the surface of an inert macroelectrode modified with microelectrodes of catalyst. Reprinted from ref. ${ }^{7}$ with permission of Elsevier.

Assuming homogeneously distributed, equal to each other, 230 hemispherical grains of the catalyst on an inert substrate, in a way 231 similar to that used by Gileadi ${ }^{16}$ to describe an ensemble of micro- 232 electrodes, the surface of the macroelectrode can be presented by an 233 idealized model, as in Fig. 2, and the number of grains per square 234 centimeter is given by:

$$
N=\frac{1}{a^{2}}
$$

It is obvious from Fig. 2 that the edge size, $a$, of a square of the 236 surface of the inert macroelectrode belonging to one such particle is 237 equal to the distance between the centers of the closest particles. If 238

$$
a=x \cdot 2 r_{\mathrm{m}}
$$

where $r_{\mathrm{m}}$ is the radius of the microelectrode and $x$ is the ratio of the 239 distance between the centers of the particles and the particle diame- 240 ter, and (33) can be rewritten in the form

$$
N=\frac{1}{4 r_{\mathrm{m}}^{2} \cdot x^{2}}
$$


The Effect of Morphology of Activated Electrodes

The surface of each hemispherical microelectrode, $S_{\mathrm{m}}$, is

$$
S_{\mathrm{m}}=2 r_{\mathrm{m}}^{2} \cdot \pi,
$$

and the working surface of catalyst per square centimeter of macro- 243 electrode, $S_{\mathrm{W}}$, is then

$$
S_{\mathrm{w}}=N \cdot S_{\mathrm{m}}=\frac{\pi}{2 x^{2}}
$$

or

$$
S_{\mathrm{w}}=\frac{2 r_{\mathrm{m}}^{2} \pi}{a^{2}}
$$

if (34) is taken into account, being dependent on the ratio $r_{\mathrm{m}} / a$.

A schematic presentation of the cross section of the diffusion 247 layer of an inert macroelectrode partially covered with small active 248 hemispherical particles is shown in Fig. 3, taking into account that 249 $\delta \gg r_{\mathrm{m}}$.

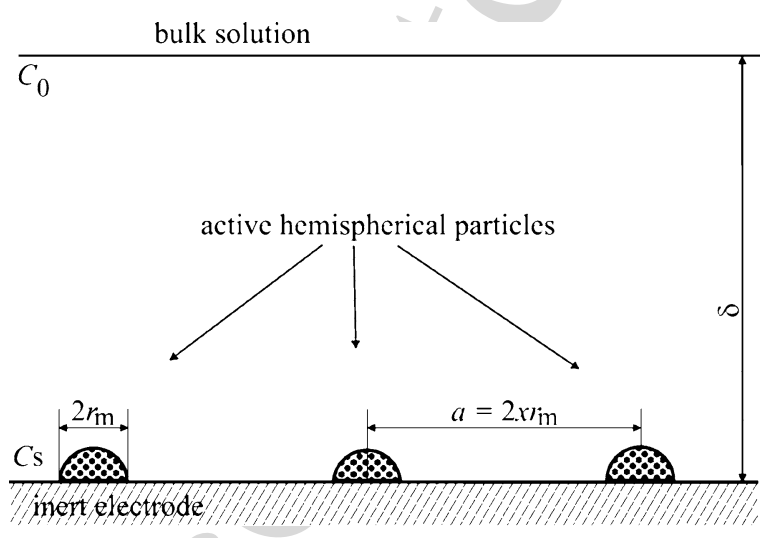

Figure 3. Schematic presentation of the cross section of the diffusion layer of a partially covered inert electrode with hemispherical active particles, where $r_{\mathrm{m}}$ is the radius of the microelectrodes, $\delta$ is the diffusion layer thickness of the macroelectrode, $C_{0}$ and $C_{\mathrm{S}}$ are the bulk and the surface concentrations of reacting ions, respectively, $x$ is the ratio of the distance between the centers of neighboring particles and the particle diameter, and $\delta \gg r$. Reprinted from ref. ${ }^{7}$ with permission of Elsevier. 
A mathematical model can be derived under the assumption 251 that the electrochemical process on the microelectrodes inside the 252 diffusion layer of a partially covered inert macroelectrode is under 253 activation control, despite the overall rate being controlled by the 254 diffusion layer of the macroelectrode. The process on the micro- 255 electrodes decreases the concentration of the electrochemically ac- 256 tive ions on the surfaces of the microelectrodes inside the diffusion 257 layer of the macroelectrode, and the zones of decreased concentra- 258 tion around them overlap, giving way to linear mass transfer to an ef- 259 fectively planar surface. ${ }^{15}$ Assuming that the surface concentration 260 is the same on the total area of the electrode surface, under steady- 261 state conditions, the current density on the whole electrode surface, 262 $j$, is given by:

$$
j=\frac{n F D\left(C_{0}-C_{\mathrm{S}}\right)}{\delta}
$$

where $n$ is the number of transferred electrons, $F$ the Faraday con- 264 stant, and $D$ is the diffusion coefficient of the reacting ion. Obvi- 265 ously, the current density from (39) is due to the difference in the 266 bulk, $C_{0}$, and surface concentration, $C_{\mathrm{S}}$, of the reactive ion. The 267 concentration dependence of the exchange current density ${ }^{22}$ is ex- 268 pressed as

$$
j_{0, \mathrm{~S}}=\left(\frac{C_{\mathrm{S}}}{C_{0}}\right)^{\gamma} j_{0},
$$

where

$$
\gamma=\frac{d \log j_{0}}{d \log C_{0}}
$$

and $j_{0}$ is the exchange current density for a surface concentration $C_{0} \quad 271$ equal to that in the bulk, and $j_{0, S}$ is the exchange current density for 272 a surface concentration $C_{\mathrm{S}}$.

The current density on the macroelectrode can also be 274 written as:

$$
j=S_{\mathrm{w}} j_{0}\left(\frac{C_{\mathrm{S}}}{C_{0}}\right)^{\gamma}\left(f_{\mathrm{c}}-f_{\mathrm{a}}\right)
$$

assuming a reversible activation controlled electrode process on the 276 hemispherical active microelectrodes on an inert substrate, where $S_{\mathrm{w}} 277$ is the active surface per square centimeter of the macroelectrode and 278 $j_{0}$ is the exchange current density on the massive active electrode, 279 standardized to the apparent electrode surface. 


\section{The Effect of Morphology of Activated Electrodes}

The current densities given by (39) and (42) are mutually equal 281 and substitution of $C_{\mathrm{S}} / C_{0}$ from (39) into (42), taking also into ac- 282 count (11) gives:

$$
j=S_{\mathrm{w}} j_{0}\left(1-\frac{j}{j_{\mathrm{L}}}\right)^{\gamma}\left(f_{\mathrm{c}}-f_{\mathrm{a}}\right)
$$

or, for $\gamma=1$, after rearranging

$$
j=\frac{S_{\mathrm{w}} j_{0}\left(f_{\mathrm{c}}-f_{\mathrm{a}}\right)}{1+\frac{S_{\mathrm{w}} j_{0}\left(f_{\mathrm{c}}-f_{\mathrm{a}}\right)}{j_{\mathrm{L}}}},
$$

where $j_{\mathrm{L}}$ is the limiting diffusion current density on the macroelec- 285 trode, standardized to the apparent electrode surface.

It is necessary to note that (44) is an approximation, because the 287 value of $\gamma$ is lower than unity. This approximation is widely used in 288 qualitative discussions, because it permits the simple mathematical 289 treatment of electrochemical processes with relatively small errors 290 and with clear physical meaning. If $\gamma \neq 1$ is included in the deriva- 291 tion of the general polarization curve equation, simple analytical so- 292 lutions are not available and numerical solutions are required. 293

It is obvious that

$$
j_{0, \text { eff }}=S_{\mathrm{W}} j_{0}
$$

is the effective value of the exchange current density relative to the 295 total surface of a partially covered electrode. It was shown ${ }^{23}$ that 296 the activity of a gold electrode modified with platinum 3D islands 297 with $72 \%$ active $\mathrm{Pt}$ sites on the electrode is approximately 25\% 298 smaller than with pure platinum. This result is in excellent agree- 299 ment with (45).

As stated earlier, (44) with $\gamma=1$ is more suitable for discus- 301 sion, but the calculation will be performed using (43) and the value 302 of $\gamma=0.5$ for the one-electron transfer process. ${ }^{7}$

Equation (44) is the polarization curve equation for a modified 304 inert electrode for $\gamma=1$. It is valid for inert substrates modified 305 by active microparticles or nanoparticles as well as by 2D and 3D 306 islands of active metal.

If

$$
f_{\mathrm{c}} \gg f_{\mathrm{a}} \text { and } \frac{S_{\mathrm{w}} j_{0} f_{\mathrm{c}}}{j_{\mathrm{L}}} \ll 1 .
$$


Equation (44) becomes:

$$
j=S_{\mathrm{w}} j_{0} f_{\mathrm{c}}
$$

and for

$$
f_{\mathrm{c}} \gg f_{\mathrm{a}} \text { and } \frac{S_{\mathrm{w}} j_{0} f_{\mathrm{c}}}{j_{\mathrm{L}}} \gg 1 .
$$

Equation (44) becomes:

$$
j \cong j_{\mathrm{L}}
$$

meaning that $j_{\mathrm{L}}$ does not depend on $S_{\mathrm{W}}$.

If

$$
f_{\mathrm{c}}>f_{\mathrm{a}} \text { and } \frac{S_{\mathrm{w}} j_{0}\left(f_{\mathrm{c}}-f_{\mathrm{a}}\right)}{j_{\mathrm{L}}} \gg 1 .
$$

Equation (15) is also valid, meaning that the process is under com- 314 plete diffusion control at all overpotentials when $j_{0} \rightarrow \infty$ if $j_{\mathrm{L}}>0315$ and $S_{\mathrm{W}}>0$.

An important conclusion can be drawn from the above deriva- 317 tions. If (46) and (47) are valid, only a part of the surface covered 318 with catalyst is active, with an exchange current density correspond- 319 ing to the massive catalyst which makes all the electrode surface 320 active but with a proportionally lower exchange current density. 321

If (48) and (15) are valid, the process enters complete diffusion 322 control, and overpotential required increases with a decrease of $S_{\mathrm{w}}$. 323

If (49) and (15) are valid, even for small $S_{\mathrm{W}}$ and overpotentials, 324 all the surface behaves as an active one if $j_{0} / j_{\mathrm{L}} \rightarrow \infty$. This means 325 that the application of a partially covered inert substrate with active 326 micro and nanoparticles will be more effective for the cases of fast 327 electrochemical reactions. It is obvious that the above reasoning is 328 valid not only for an inert substrate covered with microparticles, but 329 also for any kind of partially covered electrode.

\section{(i) Calculated Ohmic Potential Drop Is Not Included}

The real situation can be estimated by digital simulation. ${ }^{7,24}$ It 333 will be performed for example for one-electron transfer process and 334 $\beta=0.5$ and $\gamma=0.5 .^{7}$ In all cases, the apparent current density is 335 standardized to the apparent surface of modified electrode. 
The Effect of Morphology of Activated Electrodes

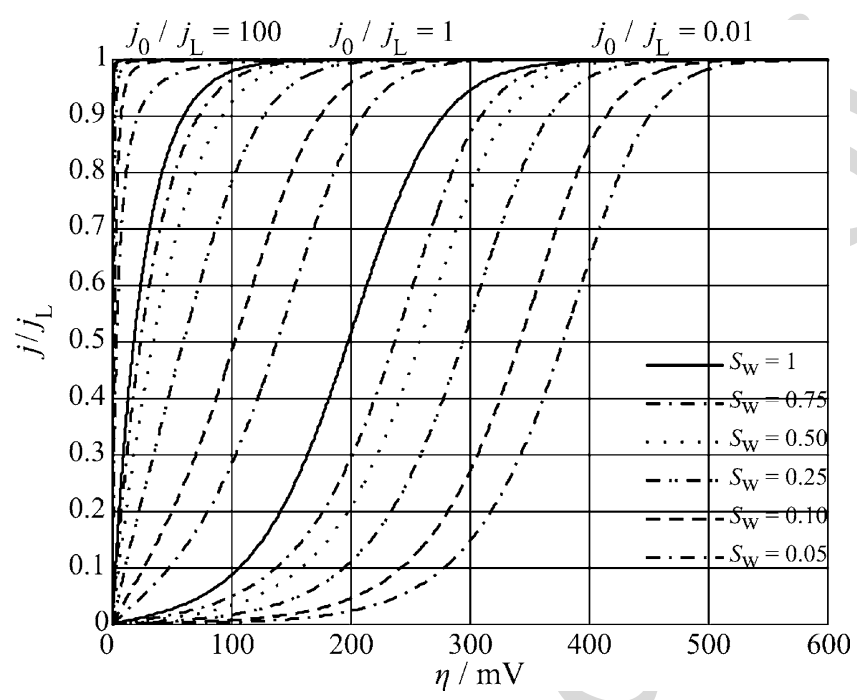

Figure 4. Dependences $j / j_{\mathrm{L}}-\eta$ calculated from (43), using $j_{0} / j_{\mathrm{L}}=100$, 1 and $0.01, S_{\mathrm{W}}=0.05,0.1,0.25,0.5,0.75$ and 1 , and $f_{\mathrm{c}}=10^{\frac{\eta}{120}}$, $f_{\mathrm{a}}=10^{-\frac{\eta}{120}}$, and $\gamma=0.5$ (Reprinted from ref. ${ }^{7}$ with permission from Elsevier).

Using (43) with $\gamma=0.5$ and $j_{0} / j_{\mathrm{L}}=100,1$, and $0.01, S_{\mathrm{W}}=337$ $0.05,0.1,0.25,0.5,0.75$, and 1 , and $f_{\mathrm{c}}=10^{\eta / 120}$ and $f_{\mathrm{a}}=338$ $10^{-\eta / 120}$, the diagrams presented in Fig. 4 are obtained. The current 339 density-overpotential dependence above each set of polarization 340 curves corresponds to $S_{\mathrm{w}}=1$. It follows from Fig. 4. that for large 341 values of $j_{0, \mathrm{eff}} / j_{\mathrm{L}}$, electrochemical polarization can probably be 342 neglected and that complete Ohmic control of the deposition process 343 can be expected, for $j_{0, \text { eff }} / j_{\mathrm{L}} \geq 100$ up to a current density about 344 $0.95 j_{\mathrm{L}}$ and for $j_{0, \text { eff }} / j_{\mathrm{L}}=0.5$ for current densities lower than $0.3 j_{\mathrm{L}} .345$

As told earlier, the shape of polarization curves does not depend 346 strongly on $S_{\mathrm{w}}$ at large $j_{0} / j_{\mathrm{L}}$ ratios. At lower ones, the important 347 effect arises.

In Fig. 5, polarization curves for $j_{0} / j_{\mathrm{L}}=100,1$, and 0.01 and 349 $S_{\mathrm{w}}=1$ (other parameters as in the caption of Fig. 4) were calculated 350 using (43) and (44).

It can be seen from Fig. 5 that the approximation of (43) by (44) 352 is acceptable at all overpotentials and ratios $j_{0} / j_{\mathrm{L}}$, being completely 353 


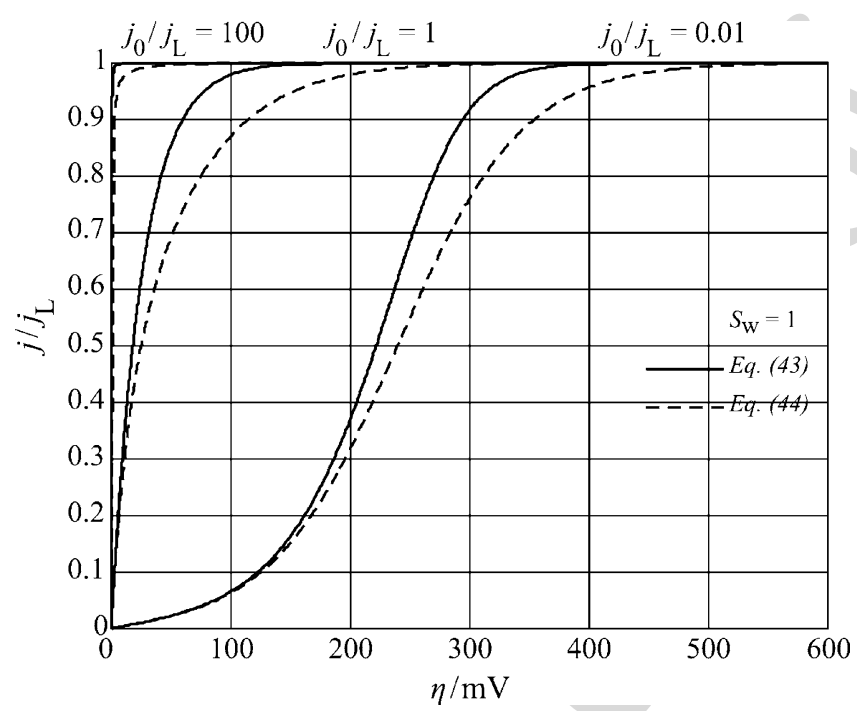

Figure 5. The same as in Fig. 4 but for $j_{0} / j_{\mathrm{L}}=100,1$ and $0.01, S_{\mathrm{W}}=1$, using (43) and $\gamma=0.5$ as well as (44). Reprinted from ref. ${ }^{7}$ with permission from Elsevier.

correct at low overpotentials for low exchange current densities (the 354 Tafel region) and at large values of $j_{0} / j_{\mathrm{L}}$ at all overpotentials. 355

Finally, (7) and (44) should be compared with each other. Taking 356 $j_{0} / j_{\mathrm{L}}=100,10,1,0.1$, and $0.01, S_{\mathrm{W}}=1$, and $f_{\mathrm{c}}=10^{\eta / 120}$ and 357 $f_{\mathrm{a}}=10^{-\eta / 120}$, the diagrams presented in Fig. 6 are obtained. It can 358 be seen that for $j_{0} / j_{\mathrm{L}} \leq 1$ diagrams computed using (7) and (44) are 359 the same. This can be explained in the following way.

Equation (7) is valid for the complete active electrode surface. 361 On the other hand, if the inert substrate is partially covered with 362 the same active material, the polarization curve equation is given 363 by (44). ${ }^{7}$

Using the recently derived equation (44), it was possible to 365 elucidate the Ohmic-controlled electrodeposition of metals by the 366 consideration of silver electrodeposition on the graphite electrode, 367 where each microelectrode was independent relative to the other 368 ones.

At larger values of $j_{0} / j_{\mathrm{L}}$ ratio, the polarization curves calculated 370 by (7) exhibit complete diffusion control being practically the same 371 as follows from (7) when $j_{0} / j_{\mathrm{L}} \rightarrow \infty$, for $f_{\mathrm{c}}>f_{\mathrm{a}}$. On the other 372 
The Effect of Morphology of Activated Electrodes

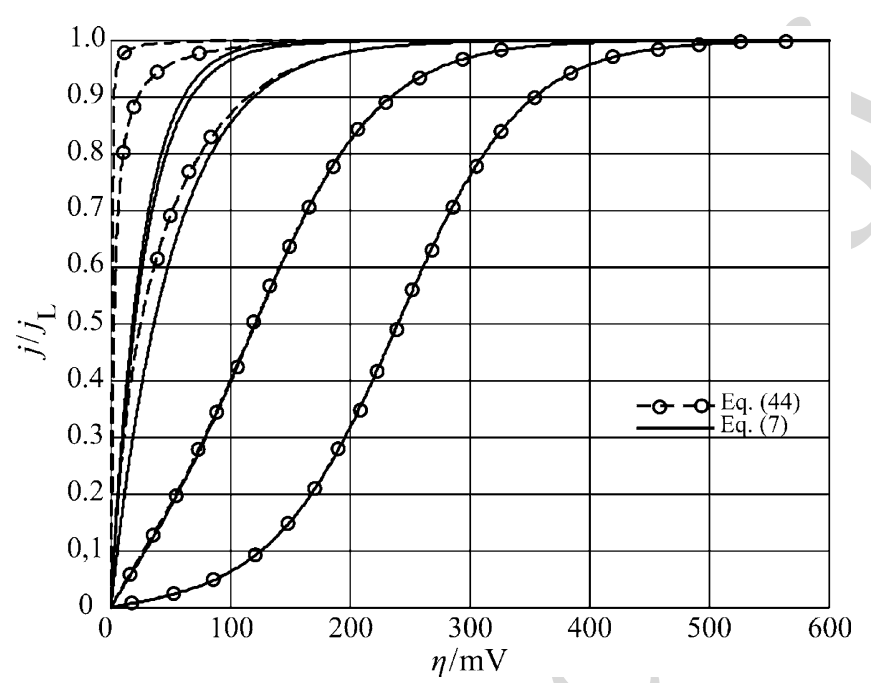

Figure 6. The comparison of polarization curves calculated using (7) and (44). From left to right side of diagram $j_{0} / j_{\mathrm{L}}$ ratio corresponds to 100,10 ,

$1,0.1$ and 0.01 , respectively; $f_{\mathrm{c}}=10^{\frac{\eta}{120}}, f_{\mathrm{a}}=10^{-\frac{\eta}{120}}$, and $S_{\mathrm{W}}=1$. Reprinted from ref. ${ }^{8}$ with permission of Elsevier.

hand, polarization curves calculated using (44) under the same con- 373 ditions become

$$
j \cong j_{\mathrm{L}} \text {. }
$$

The current densities on the massive electrode of the active ma- 375 terial and on the inert electrode activated with microelectrodes of the 376 same material become equal at

$$
S_{\mathrm{w}}=\frac{1}{1+\frac{j_{0}}{j_{\mathrm{L}}} f_{\mathrm{a}}}
$$

as follows from (7) and (44), being strongly dependent on the $j_{0} / j_{\mathrm{L}} 378$ ratio. ${ }^{8}$ Obviously, for electrochemical processes characterized with 379 $j_{0} / j_{\mathrm{L}} \gg 1$, the inert electrode will behave as a massive active one 380 even at low coverage. On the other hand, if $j_{0} / j_{\mathrm{L}} \ll 1$, it follows 381 from (50) that inert electrode will behave as activated one at $S_{\mathrm{W}}=1.382$

Naturally, during deposition on the same substrate, it can be ex- 383 pected that only small part of the electrode surface will be active 384 
and that for $j_{0} / j_{\mathrm{L}} \rightarrow \infty$ (44) is valid on both the inert and the 385 same active substrate. It can be seen from Fig. 6 that the increase of 386 the value of $j_{0} / j_{\mathrm{L}}$ ratio leads to the decrease of the electrochemical 387 overpotential. The activation part of overpotential is lost at $j_{0} / j_{\mathrm{L}}$ val- 388 ues larger than 10, while both activation and diffusion overpotential 389 vanish at $j_{0} / j_{\mathrm{L}}$ values larger than 100 (Fig. 6). In the second case, 390 the Ohmic-controlled electrochemical reaction can occur. 391

The Ohmic potential drop is not included in the polarization 392 curves depicted in Figs. 4-6.

The increase of the value of the $j_{0} / j_{\mathrm{L}}$ ratio produces large sav- 394 ing of energy.

\section{(ii) Calculated Ohmic Potential Drop Included}

The polarization curves for the electrodeposition process, which 397 include the Ohmic voltage drop, can be obtained as follows, assum- 398 ing $S_{\mathrm{w}}=1$ in all cases. ${ }^{7,9,24}$ This will be performed for a one- 399 electron transfer process and $\beta=0.5$, meaning $\gamma=0.5 .^{7} \quad 400$

Using (43) with $\gamma=0.5$ and $j_{0} / j_{\mathrm{L}}=100,10,1$, and $0.01,401$ $f_{\mathrm{c}}=10^{\eta / 120}$ and $f_{\mathrm{a}}=10^{-\eta / 120}$, and $j_{\mathrm{L}}=50$ and $10 \mathrm{~mA} \mathrm{~cm}^{-2}, 402$ the dependences presented by the dashed line in Figs. 7-10 are ob- 403 tained. The Ohmic potential drop is not included in the calculated 404 polarization curves depicted in Figs. 7-10 by the dashed line. It fol- 405 lows from Figs. 7-10 that for large values of $j_{0} / j_{\mathrm{L}}$, electrochemical 406 polarization can probably be neglected but mass-transfer limitations 407 are present in all cases, which can also be shown by differentiation 408 of (7).

On the other hand, the measured value of overpotential, $\eta_{\mathrm{m}}$, is 410 given by:

$$
\eta_{\mathrm{m}}=\eta+j \frac{L}{\kappa}
$$

due to the $I R$ error, ${ }^{25}$ where $L$ is the length of the electrolyte column 412 between the tip of a liquid capillary and the electrode and $\kappa$ is the 413 specific conductivity of the electrolyte.

For a $1 \mathrm{M}$ solution of a typical fully dissociated electrolyte, the 415 value of $\kappa$ is around $0.1 \mathrm{~S} \mathrm{~cm}^{-1}, L$ can be taken as $0.2 \mathrm{~cm}$, and $j_{\mathrm{L}}=416$ $50 \mathrm{~mA} \mathrm{~cm}^{-2}$ and $10 \mathrm{~mA} \mathrm{~cm}^{-2}$. Using these given values, as well as 417 $\kappa=0.033 \mathrm{~S} \mathrm{~cm}^{-1},(51)$, and the diagrams presented in Figs. 7-10 418 by the dashed line, polarization curves including the Ohmic potential 419 drop can be obtained, as shown in Figs. 7-10 by the solid line. $\quad 420$ 
The Effect of Morphology of Activated Electrodes

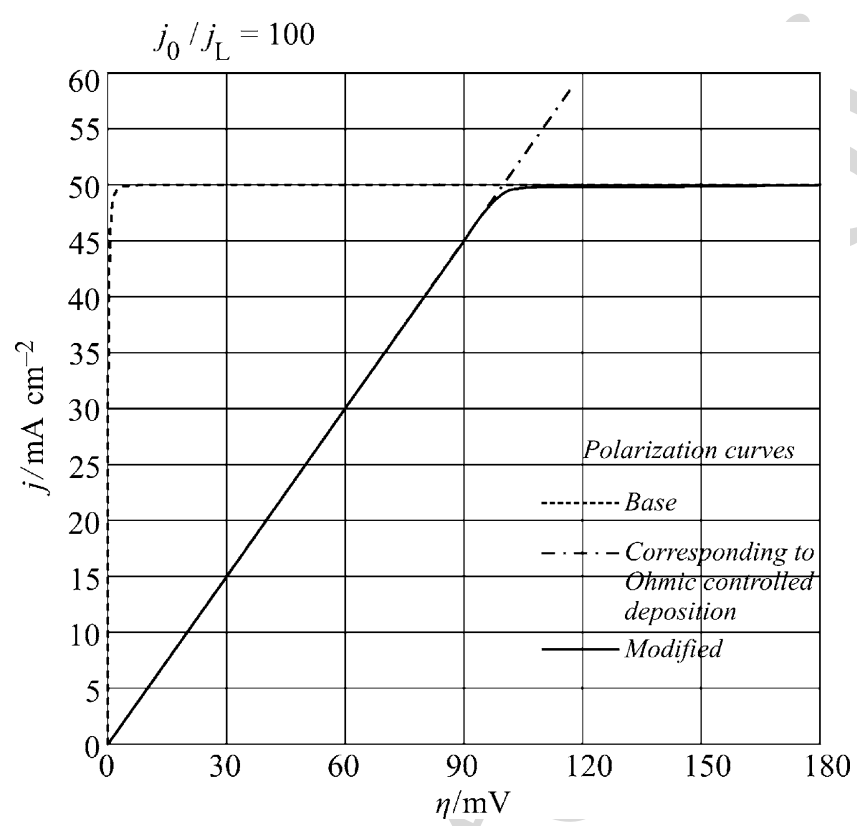

Figure 7. The dependence $j-\eta$ calculated using (43), $j_{0} / j_{\mathrm{L}}=100$, $f_{\mathrm{c}}=10^{\frac{\eta}{120}}, f_{\mathrm{a}}=10^{-\frac{\eta}{120}}, \gamma=0.5, S_{\mathrm{W}}=1$ and $j_{\mathrm{L}}=50 \mathrm{mAcm}^{-2}$, and one modified using (51), $L=0.2 \mathrm{~cm}, \kappa=0.1 \mathrm{~s} \mathrm{~cm}^{-1}$. Reprinted from ref. ${ }^{9}$ with permission from Elsevier.

Naturally, the condition of Ohmic-controlled electrochemical 421 process can be derived from (51) as:

$$
\eta \ll j \frac{L}{\kappa}
$$

or

$$
\eta \leq 0.01 j \frac{L}{\kappa} .
$$

In the case under consideration, complete Ohmic control of the 424 deposition process can be expected for $j_{0} / j_{\mathrm{L}} \geq 100$ up to a current 425 density about $0.95 j_{\mathrm{L}}$ (Fig. 7) and for $j_{0} / j_{\mathrm{L}}=10$ up to $0.6 j_{\mathrm{L}}$ (Fig. 9). 426 It is obvious from Figs. 7-10 that, regardless of the shape of the po- 427 larization curve, which depends on the $j_{0} / j_{\mathrm{L}}$ ratio and $\kappa$, a limiting 428 diffusion current density plateau is present in all cases. 
K.I. Popov et al.

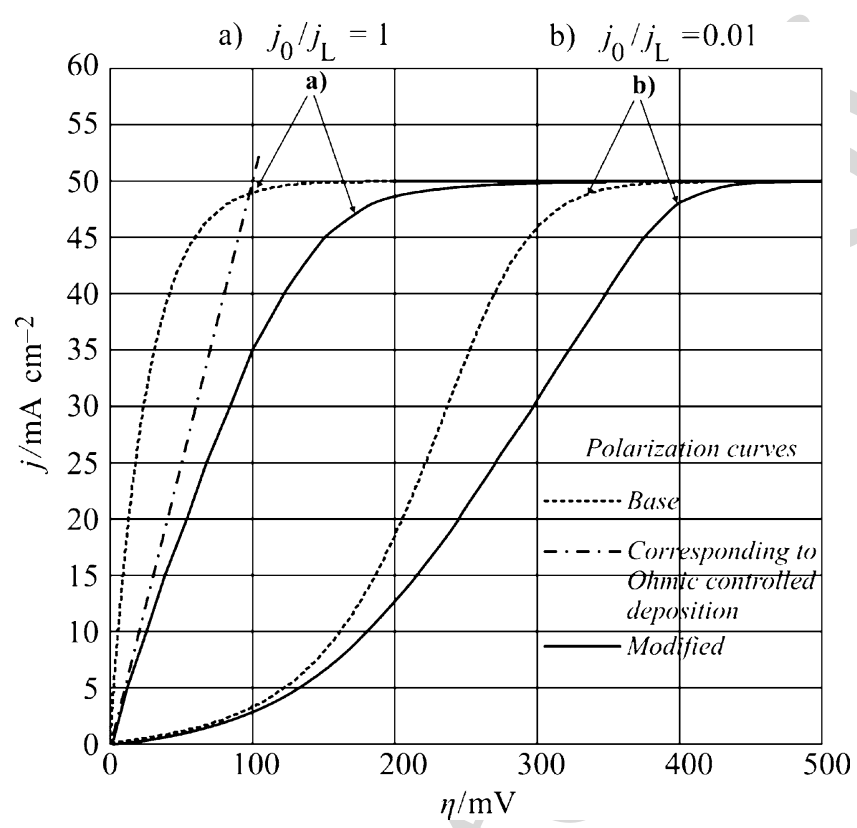

Figure 8 . The dependences $j-\eta$ calculated using (43), $j_{0} / j_{\mathrm{L}}=1$ and 0.01 , $f_{\mathrm{c}}=10^{\frac{\eta}{120}}, f_{\mathrm{a}}=10^{-\frac{\eta}{120}}, \gamma=0.5, S_{\mathrm{W}}=1$ and $j_{\mathrm{L}}=50 \mathrm{mAcm}^{-2}$, and ones modified using (51), $L=0.2 \mathrm{~cm}, \kappa=0.1 \mathrm{~s} \mathrm{~cm}^{-1}$. Reprinted from ref. ${ }^{9}$ with permission from Elsevier.

Obviously, increasing the concentration of the reacting ion and 430 decreasing the concentration of the supporting electrolyte in a simple 431 salt solution stimulates Ohmic control of the deposition process, but 432 a large value of the exchange current density seems to be the most 433 important for it (Figs. 9 and 10).

It can be noted that before the increase of the current density, 435 over the value of the limiting diffusion one, the first part of the po- 436 larization curve for silver deposition from nitrate solution ${ }^{7}$ has prac- 437 tically the same shape as that from Fig. 7 and that those from Fig. 8438 are very similar to the ones for $\mathrm{Cd}$ and $\mathrm{Cu}$ deposition. ${ }^{26}$ The value 439 of $j_{0}$ for $\mathrm{Ag}$ deposition is very large. ${ }^{27}$ In the cases of both $\mathrm{Cd}^{28} 440$ and $\mathrm{Cu}^{29}$ deposition, $j_{0}$ is considerably lower than in the case of $\mathrm{Ag} 441$ deposition. 
The Effect of Morphology of Activated Electrodes

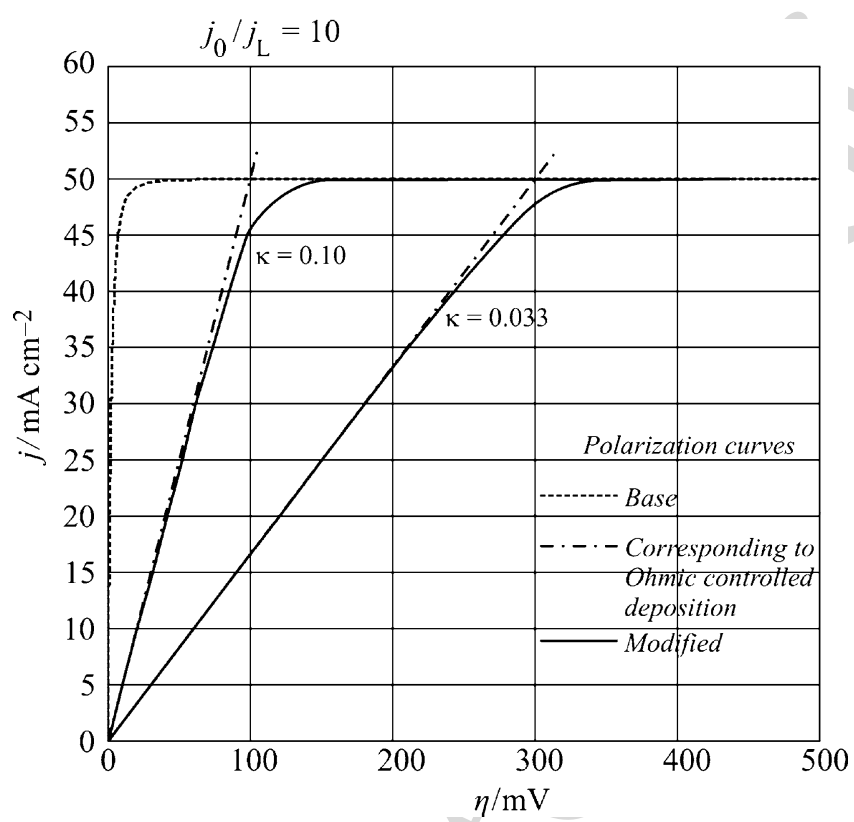

Figure 9. The dependences $j-\eta$ calculated using (43), $j_{0} / j_{\mathrm{L}}=10$, $f_{\mathrm{c}}=10^{\frac{\eta}{120}}, f_{\mathrm{a}}=10^{-\frac{\eta}{120}}, \gamma=0.5, S_{\mathrm{W}}=1$ and $j_{\mathrm{L}}=50 \mathrm{mAcm}^{-2}$, and ones modified using (51), $L=0.2 \mathrm{~cm}, \kappa=0.1$ and $0.033 \mathrm{~S} \mathrm{~cm}^{-1}$. Reprinted from ref. ${ }^{9}$ with permission from Elsevier.

The increase in the current density over the limiting diffusion 443 current in the absence of some other electrochemical process indi- 444 cates a decrease of the mass transport limitations, due to initiation 445 of growth of dendrites and further dendritic growth.

\section{Experimental Verification}

The polarization characteristic of a partially covered inert macro- 448 electrode is easy to determine, but it is very difficult or even impos- 449 sible to do the same for microelectrodes placed on it. On the other 450 hand, ${ }^{30}$ the morphology of metal electrodeposits indicates the con- 451 ditions of deposition. Hence, the type of process control on the mi- 452 croelectrodes can be derived from their morphology and correlated 453 with the polarization curve for the partially covered macroelectrode. 454 
K.I. Popov et al.

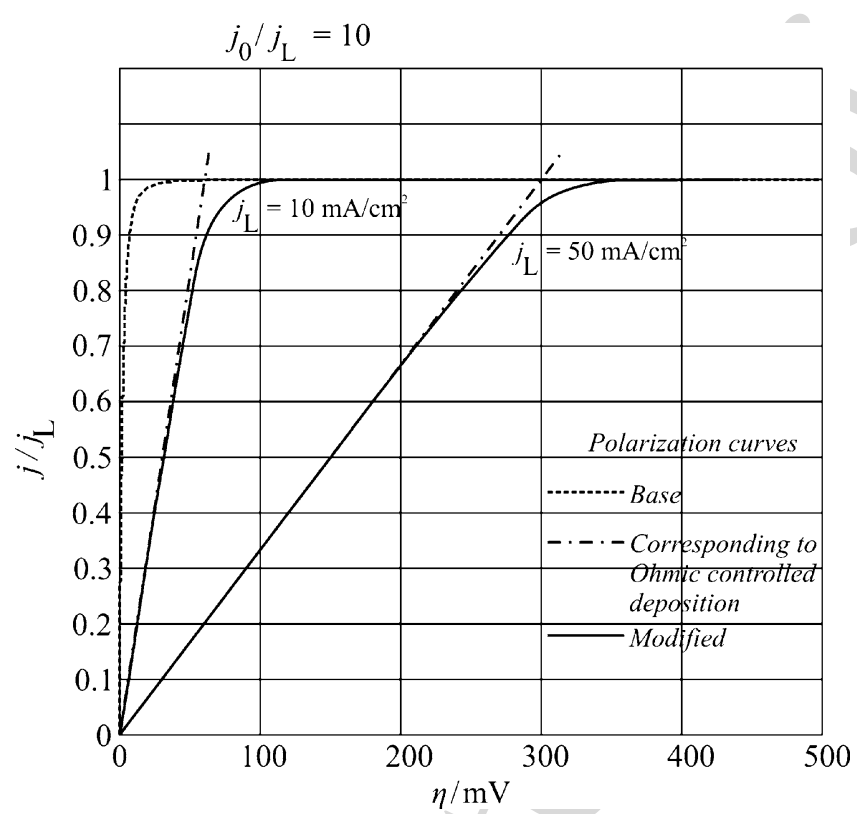

Figure 10. The dependences $j / j_{\mathrm{L}}-\eta$ calculated using (43), $j_{0} / j_{\mathrm{L}}=10$, $f_{\mathrm{c}}=10^{\frac{\eta}{120}}, f_{\mathrm{a}}=10^{-\frac{\eta}{120}}, \gamma=0.5, S_{\mathrm{W}}=1, j_{\mathrm{L}}=10 \mathrm{mAcm}^{-2}$ and $j_{\mathrm{L}}=50 \mathrm{mAcm}^{-2}$, and ones modified using $(51), L=0.2 \mathrm{~cm}$, $\kappa=0.033 \mathrm{~S} \mathrm{~cm}^{-1}$. Reprinted from ref. ${ }^{9}$ with permission from Elsevier.

There are two conditions under which the particles of active 455 metal placed on the surface of a macroelectrode can represent mi- 456 croelectrodes. The first condition is that the substrate is conducting 457 but inert relative to the process under consideration. The second one 458 is that the grains are sufficiently small to permit activation control 459 of the electrochemical process on them, making thus, mixed over- 460 all control, as in the case of the tips of growing dendrites, ${ }^{11,12,31}$ or 461 during the induction time of the formation of spongy deposits. ${ }^{32-34} 462$

As already stated, the nuclei behave as microelectrodes in the 463 initial stage of electrodeposition of metals onto inert substrates. ${ }^{33}$ If 464 nucleation exclusion zones around nuclei are formed, ${ }^{35,36}$ an inert 465 substrate can be partially covered even at long deposition times, due 466 to the nucleation exclusion zones overlapping, which results in the 467 formation of granular electrodeposits. ${ }^{37,38}$ In this way, a granular 468 


\section{The Effect of Morphology of Activated Electrodes}

silver deposit on a platinum or graphite electrode can represent the 469 ideal physical model of an inert substrate covered by nanoparticles. 470

It was shown earlier ${ }^{32,33}$ that the mechanism of spongy deposit 471 formation can be successfully illustrated by a physical model and 472 that the calculations derived for the real system can be applied for the 473 model and vice versa. The formation of nucleation exclusion zones 474 is illustrated by the physical model ${ }^{35}$ as well as by the effect of the 475 exchange current density of the deposition process on the radii of 476 them $^{36,39}$ with fair agreement with the experimental data. In addi- 477 tion, the physical simulation ${ }^{40,41}$ of the periodicity in the surface 478 structure of a polycrystalline electrolytic deposit ${ }^{42}$ is also possible. 479 As nucleation rings appear due to the supersaturation zones, ${ }^{40}$ the 480 mutual effect of the nuclei at the moment of their formation confirms 481 directly that the process on the nanoscale can also be elucidated by 482 an appropriate physical model. Besides, even the electrochemical 483 treatment of tumors in human tissue can be simulated by the elec- 484 trochemical model. ${ }^{43}$ Hence, it can be expected that physical mod- 485 eling will also be useful in the consideration of mass transfer on 486 an inert electrode partially covered with small particles of an active 487 metal. The kind of a process control on the microelectrodes inside 488 the diffusion layer of a partially covered inert electrode could be esti- 489 mated, and a mathematical model of the overall process on a partially 490 covered electrode proposed. 491

The electrolyte solutions used in further experiments were: 492 $0.5 \mathrm{M} \mathrm{AgNO}_{3}$ in $0.2 \mathrm{M} \mathrm{HNO}_{3}$ (nitrate bath) and $0.1 \mathrm{M} \mathrm{AgNO} 3493$ in $0.5 \mathrm{M}\left(\mathrm{NH}_{4}\right)_{2} \mathrm{SO}_{4}$ (ammonium bath). The overpotential was in- 494 creased from initial to the final value and held for $30 \mathrm{~s}$ before mea- 495 surement in all cases during the polarization measurements. 496

The polarization curves for/silver electrodeposition are pre- 497 sented in Fig. 11.

It is obvious from Fig. 11 that the polarization curves for deposi- 499 tion on the compact silver layer and on the uncovered graphite elec- 500 trode are practically the same. In both cases, the Ohmic-controlled 501 deposition is obvious. This can mean that the deposition on the 502 graphite electrode coated with silver also initiates by nucleation. 503 Besides, the grain of silver can be seen from Fig. 12a. In both cases, 504 an overpotential of $120 \mathrm{mV}$ belongs to the region in which a slight 505 decline in the slope of the polarization curve indicates an increased 506 degree of diffusion control. At overpotentials larger than $140 \mathrm{mV}$, a 507 strong increase in the current density with increasing overpotential 508 occurs because of the initiation of dendritic growth. ${ }^{11,12}$ 
K.I. Popov et al.

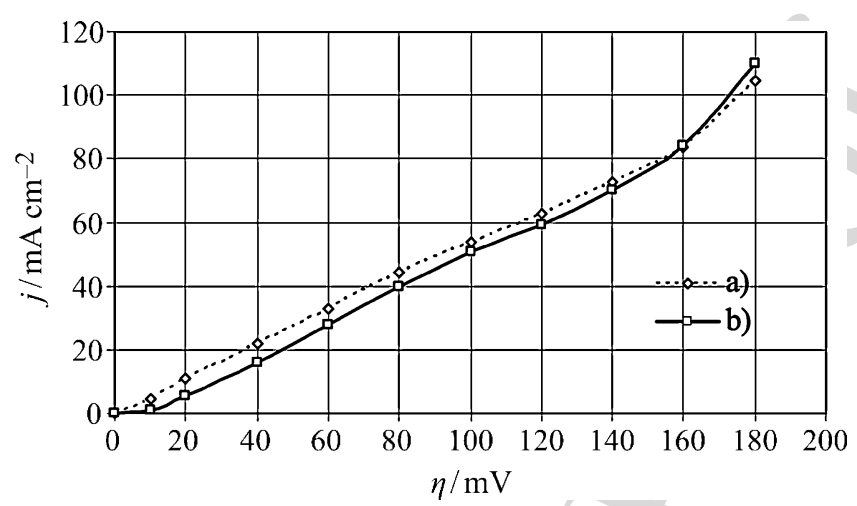

Figure 11. Polarization curves for silver electrodeposition from the nitrate solution on: (a) a graphite electrode previously plated with silver from the ammonium solution; (b) on an uncovered graphite electrode. Reprinted from ref. ${ }^{7}$ with permission from Elsevier.
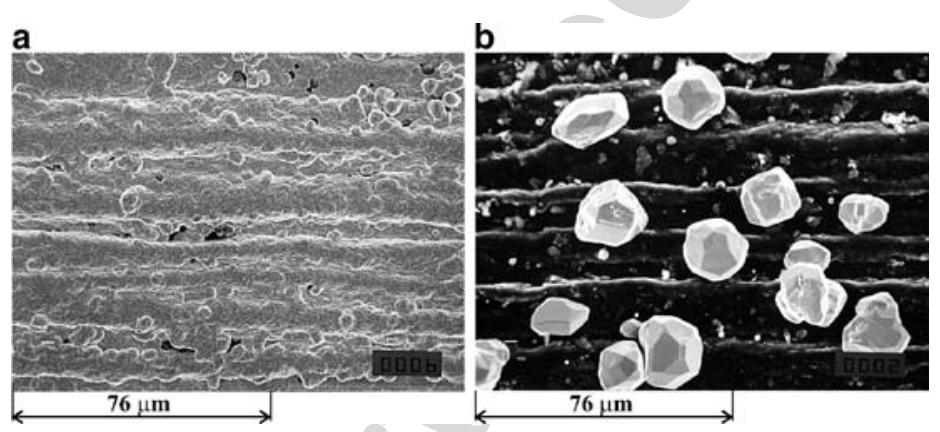

Figure 12. The physical model of a partially covered inert electrode with active grains and a completely covered inert electrode: (a) a graphite electrode completely covered by deposition from the ammonium bath; current density on the electrode completely covered with silver was $62.5 \mathrm{~mA} \mathrm{~cm}^{-2}$ at an overpotential of $120 \mathrm{mV}$ in the nitrate solution; magnification $500 \times$; (b) the silver deposit on the graphite electrode after the polarization measurements ended at an overpotential of $120 \mathrm{mV}$ in the nitrate solution; magnification $500 \times$; current density on such electrode was $59.4 \mathrm{~mA} \mathrm{~cm}^{-2}$ at the same overpotential in the nitrate solution. Reprinted from ref. ${ }^{7}$ with permission of Elsevier.

The polarization curves on platinum electrodes were very simi- 510 lar to those obtained on graphite ones. ${ }^{7}$

An SEM microphotograph of the silver deposit obtained after 512 polarization measurement up to an overpotential of $120 \mathrm{mV}$ on an 513 


\section{The Effect of Morphology of Activated Electrodes}

uncovered graphite electrode is shown in Fig. 12b. The electrode 514 surface is partially covered because of the overlapping of the nu- 515 cleation exclusion zones, being, as already told, the ideal physical 516 model of a partially covered inert electrode. $\quad 517$

The surface of completely covered graphite electrode by depo- 518 sition from ammonium bath is shown in Fig. 12a. The regular crystal 519 form of the grains in Fig. 12b confirms that the deposition on the mi- 520 croelectrodes is not under diffusion control, ${ }^{44,45}$ despite the overall 521 deposition rate being determined by diffusion to the macroelectrode. 522

The current density on the electrode from Fig. 12b, with a cover- 523 age of about $20 \%$, is practically the same as on a completely covered 524 graphite electrode, as can be seen from Fig. 11 at an overpotential of 525 $120 \mathrm{mV}$. This is because the exchange current density for the silver 526 electrodeposition process from nitrate baths is extremely large. ${ }^{27,46} 527$

A similar situation appears in silver electrodeposition on 528 platinum. $^{7}$

The surface layers of silver obtained by electrodeposition from 530 an ammonium bath on a graphite electrode are shown in Fig. 13. 531

The $S_{\mathrm{W}}$ in Fig. $13 \mathrm{a}$ is about $20 \%$ and the current density at 532 $30 \mathrm{mV}$ is about $40 \%$ of the current density on a completely covered 533

a
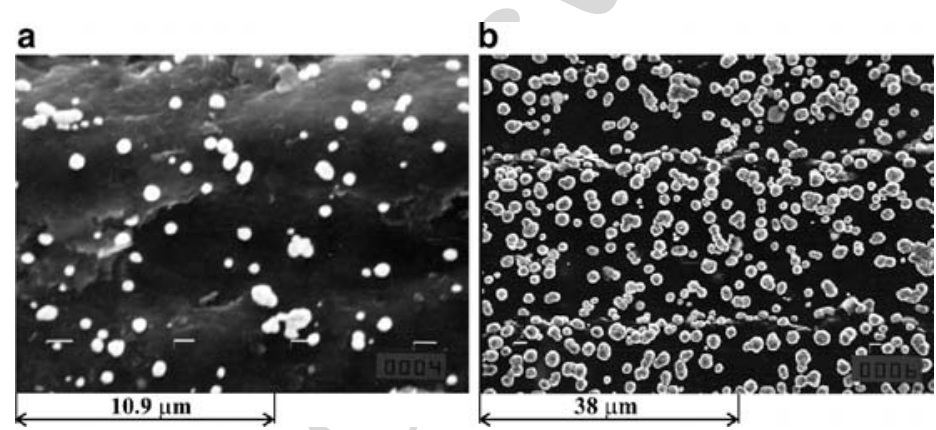

Figure 13. The silver layer on a graphite electrode obtained by electrodeposition from the ammonium solution at an overpotential of $100 \mathrm{mV}$ for: (a) $2.5 \mathrm{~s}$. The current density on this electrode in the ammonium solution at an overpotential of $30 \mathrm{mV}$ was $0.5 \mathrm{~mA} \mathrm{~cm}^{-2}$. Magnification 3,500×; (b) $60 \mathrm{~s}$. The current density on this electrode in the ammonium solution at an overpotential of $30 \mathrm{mV}$ was $1.0 \mathrm{~mA} \mathrm{~cm}^{-2}$. The current density on a completely covered graphite electrode after a pulse of an overpotential of $150 \mathrm{mV}$ for $3 \mathrm{~s}$ and deposition at an overpotential of $100 \mathrm{mV}$ for $10 \mathrm{~min}$ was $1.25 \mathrm{~mA} \mathrm{~cm}^{-2}$ at the same potential. Magnification $1,000 \times$. Reprinted from ref. ${ }^{7}$ with permission from Elsevier. 
inert substrate in ammonium solution. In Fig. 13b, the $S_{\mathrm{w}}$ is more 534 than $90 \%$ and current density is $80 \%$ of the current density on a com- 535 pletely covered electrode. This is in accordance with (44) and (47), 536 because the exchange current density for the silver electrodeposi- 537 tion process from ammonium solutions is considerably lower than 538 the corresponding limiting diffusion current density. ${ }^{47} \quad 539$

The above facts are a fair illustration of the concluding remarks 540 in the previous section. It is necessary to note that the uncovered part 541 of the inert substrate after nucleation at larger potentials negative to 542 the reference electrode remains inert at lower ones.

\section{The Required Quantity of Active Substance}

Finally, the required quantity of catalyst for the activation of an inert 545 substrate can now be estimated as follows. The volume of hemi- 546 spherical microelectrode, $V_{\mathrm{m}}$, is given by

$$
V_{\mathrm{m}}=\frac{2}{3} r_{\mathrm{m}}^{3} \cdot \pi
$$

and the mass of such a grain is then

where $\rho$ is the density of catalyst, and the mass of catalyst per square 549 centimeter of the inert electrode, $m$, is

$$
m=N \cdot m_{\mathrm{m}}=\frac{r_{\mathrm{m}} \cdot \pi \cdot \rho}{6 x^{2}}
$$

or, taking into account (37) and (50)

$$
m=\frac{r_{\mathrm{m}} \cdot \rho}{3} S_{\mathrm{W}}=\frac{r_{\mathrm{m}} \cdot \rho}{3} \cdot \frac{1}{1+\frac{j_{0}}{j_{\mathrm{L}}} f_{\mathrm{a}}} .
$$

Equation (57) is valid for the cathodic processes. In similar way, 552 the corresponding equation for the anodic ones can be derived. $\quad 553$

It is obvious from (57) that the quantity of catalyst in the form 554 of small hemispherical grain required to transform an inert electrode 555 into an active one decreases rapidly with decrease in size of the par- 556 ticles, for one and the same $S_{\mathrm{w}}$, as well as with the increase of the 557 
The Effect of Morphology of Activated Electrodes

$j_{0} / j_{\mathrm{L}}$ value for the process taking place on it. Hence, $(57)$ can be 558 considered as fundamental one for electrocatalysis by active parti- 559 cles on inert electrodes.

The current density on the graphite electrode partially covered 561 with silver grains obtained from the nitrate solution by a pulse of an 562 overpotential of $100 \mathrm{mV}$ for $20 \mathrm{~ms}$ and by further growth at an over- 563 potential of $40 \mathrm{mV}$ for $30 \mathrm{~s}$ (Fig. 14a) is practically the same as the 564 current density on a massive silver electrode at an overpotential of 565 $40 \mathrm{mV}$. The same occurs with a graphite electrode covered with sil- 566 ver grains by a pulse of an overpotential of $500 \mathrm{mV}$ for $5 \mathrm{~ms}$ and by 567 further growth at an overpotential of $40 \mathrm{mV}$ for $5 \mathrm{~s}$ (Fig. 14b). It can 568 be seen that the deposits depicted in Fig. 14a and this in Fig. 14b, 569

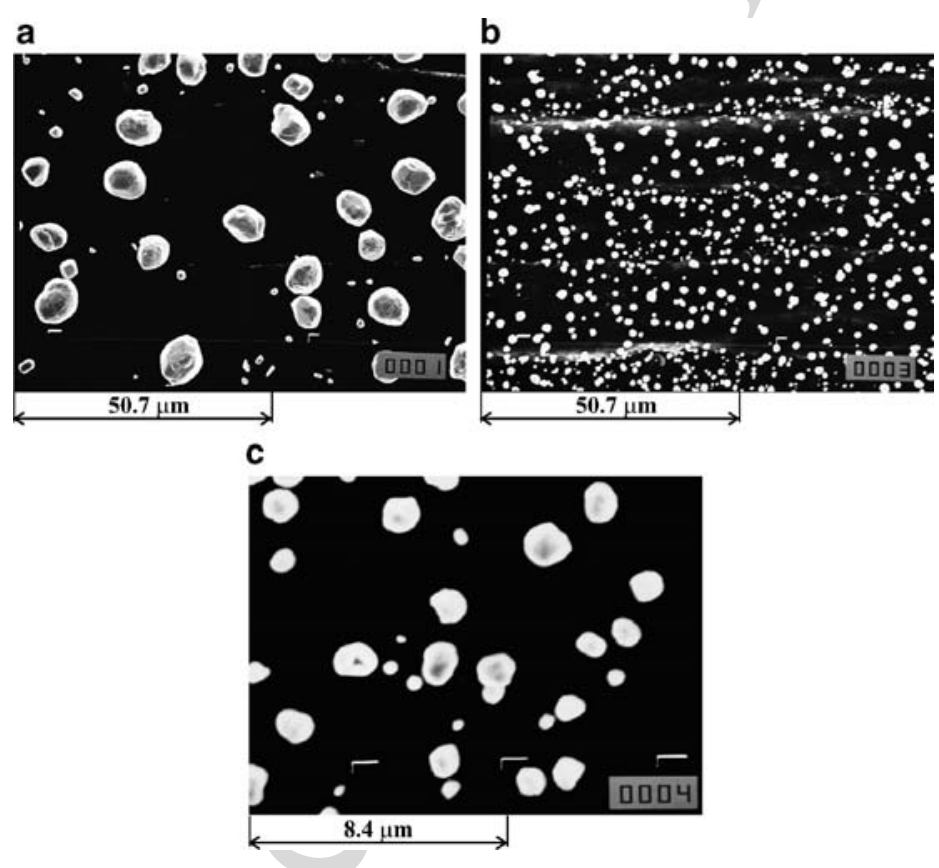

Figure 14. Silver electrodeposits on a graphite electrode obtained from the nitrate solution: (a) pulse of an overpotential of $100 \mathrm{mV}$ for $20 \mathrm{~ms}$ and further growth at an overpotential of $40 \mathrm{mV}$ for $30 \mathrm{~s}$. Magnification $750 \times$; (b) pulse of an overpotential of $500 \mathrm{mV}$ for $5 \mathrm{~ms}$ and further growth at an overpotential of $40 \mathrm{mV}$ for $5 \mathrm{~s}$; magnification $750 \times$; (c) the same as in (b), but under a magnification of 4,500×. Reprinted from ref. ${ }^{7}$ with permission of Elsevier. 
under the same magnification, are very different. In Fig. 14c, the 570 deposit from Fig. 14b, but under a considerably larger magnification, 571 is shown, being very similar to that depicted in Fig. 14a. $\quad 572$

It seems to be practically identical with the deposit shown in 573 Fig. $14 \mathrm{a}$, which can also be concluded from calculated $x / 2 r_{\mathrm{m}}$ val- 574 ues, being 2.5 for the deposit shown in Fig. 14a and 2.9 for that 575 shown in Fig. 14b. It is obvious that despite the grains being many 576 times smaller, their mutual relations are similar to those shown in 577 Fig. 14a, producing the same activity with a many times lower quan- 578 tity of electrodeposited metal, which is in the accordance with (37) 579 and (38).

In both cases, the current density on the partially covered elec- 581 trode was $21 \mathrm{~mA} \mathrm{~cm}^{-2}$. The current density on a completely covered 582 graphite electrode in the nitrate solution was $22 \mathrm{~mA} \mathrm{~cm}^{-2}$ at an over- 583 potential of $40 \mathrm{mV}$. 584

The electrodeposition of metals on inert substrates by fast elec- 585 trochemical reactions permits the physical modeling of processes on 586 partially covered inert substrates due to formation of nucleation ex- 587 clusion zones around the growing grains. Regardless of the continu- 588 ous change of the size of the microelectrodes during the deposition 589 process, the current density and morphology can be correlated to 590 each other after any deposition time. It is also the only way of deter- 591 mining the type of process control on the microelectrodes. 592

Hence, the procedure described above could be unavoidable for 593 the elucidation of the polarization behavior of an inert electrode 594 partially covered with small active grains, probably with nanopar- 595 ticles, too.

\section{INERT ELECTRODES ACTIVATED WITH DENDRITES}

\section{Large Level of Coarseness}

From the electrochemical point of view, a dendrite can be defined as 599 an electrode surface protrusion that grows under activation or mixed 600 control, while deposition to the flat part of the electrode surface is 601 under complete diffusion control. ${ }^{11-13,48} 602$

Considering the model of surface irregularities shown in Fig. 1, 603 the surface irregularities are buried deep in the diffusion layer, which 604 is characterized by a steady linear diffusion to the flat portion of 605 completely active surface. 


\section{The Effect of Morphology of Activated Electrodes}

If the protrusion does not affect the outer limit of the diffusion 607 layer, i.e., if $\delta \gg h$, the limiting diffusion current density to the tip 608 of the protrusion from Fig. $1, j_{\mathrm{L}}$,tip , is given by ${ }^{20}$

$$
j_{\mathrm{L}, \text { tip }}=j_{\mathrm{L}}\left(1+\frac{h}{r}\right) .
$$

Substitution of $j_{\mathrm{L}, \text { tip }}$ from (24) into (7) produces for $h / r \gg 1: \quad 610$

$$
j_{\text {tip }}=j_{0, \text { tip }}\left(f_{\mathrm{c}}-f_{\mathrm{a}}\right),
$$

where $j_{0, \text { tip }}$ is the exchange current density at the tip of a protrusion. 611

Obviously, deposition to the tip of such protrusion inside the 612 diffusion layer is activation controlled relative to the surrounding 613 electrolyte, but it is under mixed activation-diffusion control relative 614 to the bulk solution.

If deposition to the flat part of electrode is a diffusion-controlled 616 process and assuming a linear concentration distribution inside the 617 diffusion layer, the concentration $C$ at the tip of a protrusion can be 618 given by (22). ${ }^{12}$

$$
C=C_{0} \frac{h}{\delta} .
$$

According to Newman, ${ }^{22}$ the exchange current density at the tip of 620 a protrusion is given by

$$
j_{0, \text { tip }}=j_{0}\left(\frac{C}{C_{0}}\right)^{\gamma}
$$

or

$$
j_{0, \text { tip }}=j_{0}\left(\frac{h}{\delta}\right)^{\gamma}
$$

because of (22).

Taking into account (58), the current density to the tip of a pro- 623 trusion is then given by

$$
j_{\text {tip }}=j_{0}\left(\frac{h}{\delta}\right)^{\gamma}\left(f_{\mathrm{c}}-f_{\mathrm{a}}\right)
$$

being under mixed control due to the $(h / \delta)^{\gamma}$ term, which takes into 626 account the concentration dependence of $j_{0 \text {,tip }}$, expressing in this 627 way a mixed-controlled electrodeposition process. 
K.I. Popov et al.

Outside the diffusion layer $h \geq \delta$, and (61) becomes:

$$
j_{\text {tip }}=j_{0}\left(f_{\mathrm{c}}-f_{\mathrm{a}}\right)
$$

indicating pure activation control, as the $(h / \delta)^{\gamma}$ term is absent.

On the other hand, according to Wranglen, ${ }^{49}$ a dendrite is a 631 skeleton of a monocrystal and consists of a stalk and branches, 632 thereby resembling a tree.

Dendritic growth occurs selectively at three types of growth 634 sites: at screw dislocations ${ }^{12}$ on the indestructible reentrant groove 635 formed in the twinning process ${ }^{50}$ and, in the case of a hexagonal 636 close-packed lattice, growth leading to the formation of low index 637 planes. ${ }^{51}$ Deposition to the tip of a screw dislocation can be theo- 638 retically considered as diffusion to a point and in other two cases 639 as diffusion to a line. In any case, the conditions requested for 640 activation-controlled deposition are fulfilled. ${ }^{12,52-54} 641$

The current density to the tip of a protrusion formed on the 642 flat part of the electrode surface growing inside the diffusion layer 643 should be larger than the corresponding limiting diffusion current 644 density. ${ }^{21}$ Hence, if $\delta \gg h$ and

$$
j_{\mathrm{L}}<j_{\text {tip }},
$$

the protrusion grows as a dendrite.

In accordance with (63), instantaneous dendrite growth is pos- 647 sible at overpotentials larger than some critical value, $\eta_{\mathrm{cr}}$, which can 648 be derived from (61) as shown by Popov et al. ${ }^{55}$

$$
\eta_{\mathrm{cr}}=\frac{b_{\mathrm{c}}}{2.3} \ln \frac{j_{\mathrm{L}}}{j_{0}}\left(\frac{\delta}{h}\right)^{\gamma}
$$

for $f_{\mathrm{c}} \gg f_{\mathrm{a}}$, where $h$ and $\delta$ are the protrusion height and the dif- 650 fusion layer thickness, respectively. For very fast processes, when 651 $j_{0} / j_{\mathrm{L}} \gg 1$, i.e., if $f_{\mathrm{c}} \approx f_{\mathrm{a}}$ but $f_{\mathrm{c}}>f_{\mathrm{a}},(61)$ becomes:

$$
\eta_{\mathrm{cr}}=\frac{R T}{n F} \frac{j_{\mathrm{L}}}{j_{0}}\left(\frac{\delta}{h}\right)^{\gamma}
$$

meaning that in the case of Ohmic-controlled reactions, dendritic 653 growth can be expected at very low overpotentials, or better to say, 654 if $j_{0} \rightarrow \infty$, instantaneous dendritic growth is possible at all overpo- 655 tentials if only mass-transfer limitations are taken into consideration. 656 


\section{The Effect of Morphology of Activated Electrodes}

In fact, dendrite propagation under such conditions is under 657 diffusion and surface energy control and $\eta_{\mathrm{cr}}$ is then given by: ${ }^{11,21} 658$

$$
\eta_{\mathrm{cr}}=\frac{8 \sigma V}{n F h}
$$

where $\sigma$ is the metal surface energy and $V$ is the molar volume of 660 the metal.

Hence, a critical overpotential for initiation dendritic growth is 662 also expected in such cases, being of the order of few millivolts. ${ }^{21,56} 663$

The initiation of dendritic growth is followed by an increase of 664 the deposition current density, and the overall current density will be 665 larger than the limiting diffusion current on a flat active electrode. 666 Based on the above discussion, the polarization curve equation in 667 the Ohmic-controlled electrodeposition of metals can be determined 668 now by: ${ }^{9}$

$$
\begin{gathered}
j=\frac{\kappa \eta}{L} \quad \text { for } 0 \leq \eta<j_{\mathrm{L}} \frac{L}{\kappa}, \\
j=j_{\mathrm{L}} \quad \text { for } j_{\mathrm{L}} \frac{L}{\kappa} \leq \eta<\eta_{\mathrm{cr}}+j_{\mathrm{L}} \frac{L}{\kappa}, \\
j=j_{\mathrm{L}} \theta+(1-\theta) j_{0} \frac{\left(f_{\mathrm{c}}-f_{\mathrm{a}}\right)}{N} \sum_{i=1}^{i=N}\left(\frac{h_{i}}{\delta}\right)^{\gamma} \quad \text { for } \eta_{\mathrm{cr}} \leq \eta,
\end{gathered}
$$

where $N=N(t)$ is the number of dendrites and $\theta=\theta(t) \leq 1,670$ where $\theta$ is the coverage of the electrode surface with dendrites. 671

Equation (67a) describes the linear part of the polarization 672 curves for tin, ${ }^{57}$ silver, ${ }^{7}$ and lead ${ }^{58}$ deposition and (67b) foresees the 673 inflection point in the cases when $\eta_{\mathrm{cr}}$ is low and the resistance of the 674 electrolyte large. Finally, (67c) describes the part of the polarization 675 curve after initiation of dendrite growth. 676

It is interesting to note that $(67 \mathrm{c})$ describes qualitatively the 677 increase of the apparent current density over the value of the lim- 678 iting diffusion current density after initiation of dendritic growth, 679 since the quantitative treatment of the polarization characteristics in 680 the presence of dendrite growth is simply impossible. This is be- 681 cause dendrites can have a variety of unpredictable structures. In this 682 way, the results of $\mathrm{Ibl}$ and Schadegg, ${ }^{59}$ Diggle et al., ${ }^{12}$ and Popov 683 et al., ${ }^{21}$ as well as the Ohmic-controlled deposition of tin, ${ }^{57}$ silver, ${ }^{7} 684$ and lead, ${ }^{58}$ could be explained qualitatively. 
Thus, instead of a limiting diffusion current density plateau, a 686 curve inflection point or a short inclined plateau can be expected 687 on the polarization curve in Ohmic-controlled electrodeposition of 688 metals, as observed in the case of silver electrodeposition from ni- 689 trate solutions. The exchange current density of the silver reaction in 690 nitrate electrolytes is sufficiently large to permit Ohmic-controlled 691 deposition as well as dendritic growth at low overpotentials. ${ }^{27}$ After 692 a linear increase of the deposition current density with increasing 693 overpotential, an exponential increase after the inflection point ap- 694 pears, meaning the elimination of mass-transfer limitations due to 695 the initiation of dendritic growth.

The polarization curve for silver electrodeposition from nitrate 697 solution, $0.5 \mathrm{M} \mathrm{AgNO}_{3}$ in $0.2 \mathrm{M} \mathrm{HNO}_{3}$, onto a graphite electrode is 698 shown in Fig. 15. As shown earlier, ${ }^{7}$ the polarization curves for sil- 699 ver deposition from nitrate solution onto a graphite electrode and on 700 graphite covered with a nonporous surface film of silver (hence, on 701 a massive silver electrode) are practically the same. The polarization 702 curve in Fig. 15 is very similar to that in Fig. 7, which means that 703 mass-transfer limitations were decreased or even eliminated. The 704 SEM photomicrographs of the deposit corresponding to the points 705 from Fig. 15 are shown in Fig. 16.

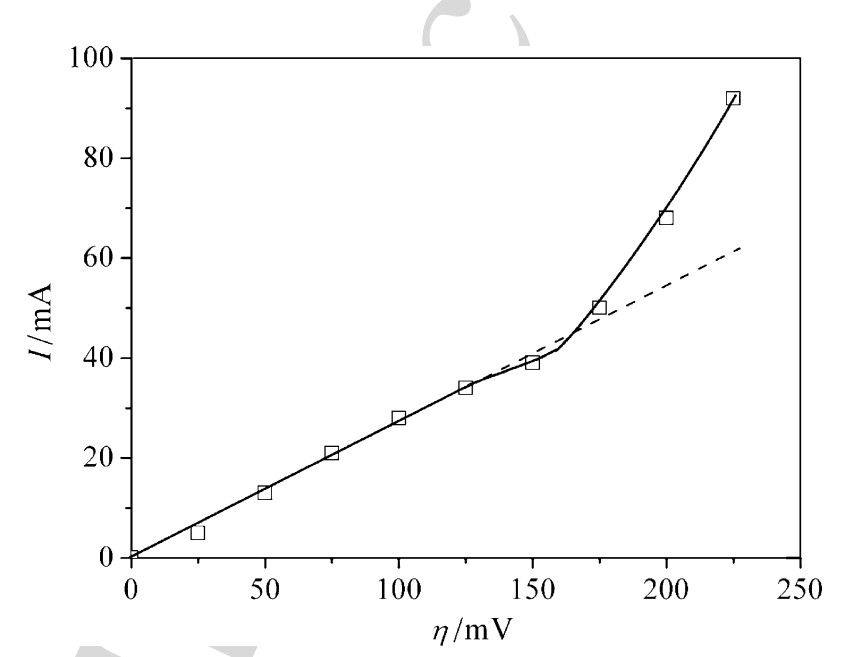

Figure 15. The polarization curve for silver electrodeposition from nitrate solution on a graphite electrode. Reprinted from ref. ${ }^{9}$ with permission from Elsevier. 

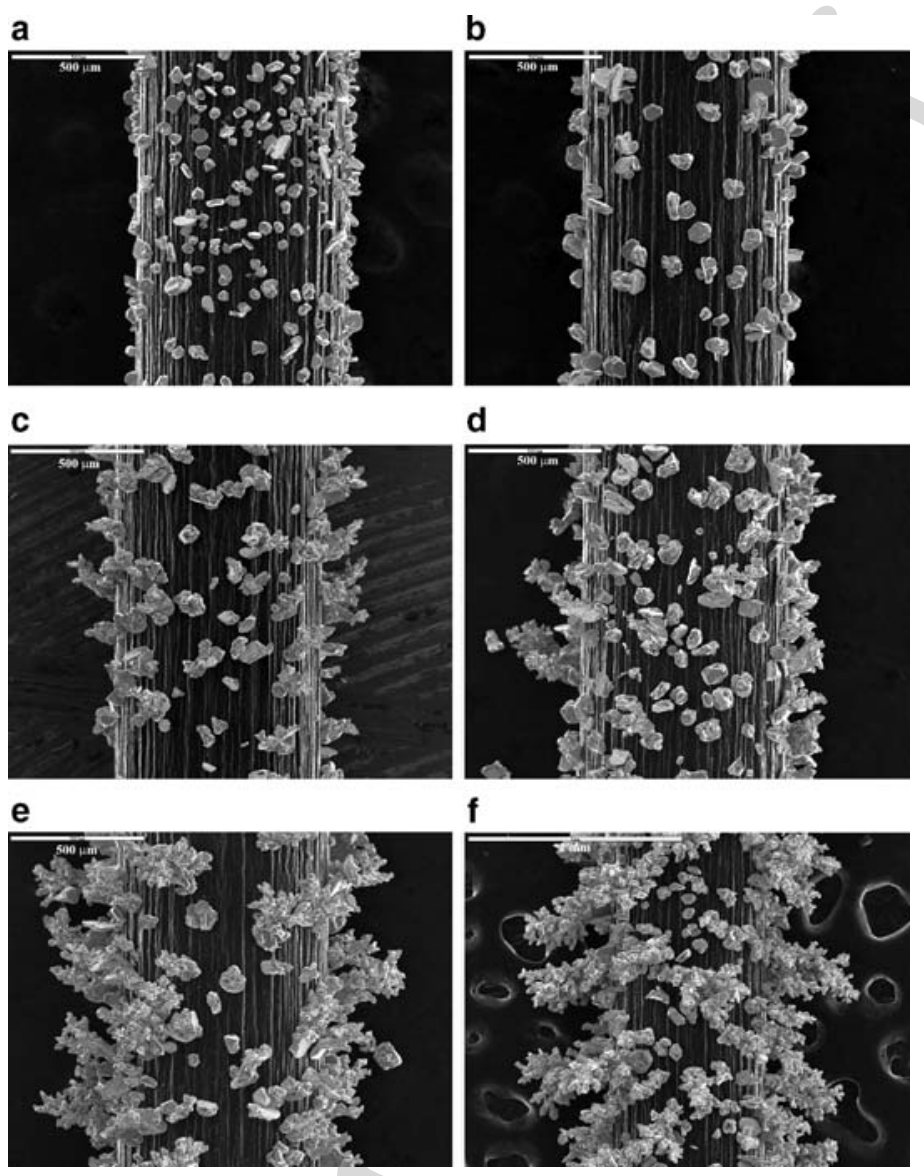

Figure 16. The SEM photomicrographs of the silver deposit obtained on a graphite electrode obtained after the recording of the current at different overpotentials in polarization measurements: (a) 100; (b) 125; (c) 150; (d) 175; (e) 200; and (f) $225 \mathrm{mV}$. Reprinted from ref. ${ }^{9}$ with permission from Elsevier.

It can be seen from Figs. 15 and 16a that at an overpotential of 707 $100 \mathrm{mV}$, only grains ${ }^{9}$ can be seen, which means that the deposition 708 was not under diffusion control. It follows from Figs. 15 and 16b 709 that deposition at an overpotential of $125 \mathrm{mV}$ is still out of diffu- 710 sion control. At $150 \mathrm{mV}$, the current density is somewhat lower than 711 that which could be expected from the linear dependence of current 712 
on overpotential. This indicates not only the initiation of diffusion 713 control of the deposition process but also the initiation of dendrite 714 growth, which compensates the mass-transfer limitations, as can be 715 seen from Figs. 15 and 16c. The point corresponding to an overpo- 716 tential of $150 \mathrm{mV}$ can be considered as the inflection point of the 717 polarization curve in Fig. 15.

At overpotentials larger than $175 \mathrm{mV}$, the current density is con- 719 siderably larger than the one expected from the linear dependence 720 of current on overpotential. The formation of dendritic deposits 721 (Fig. 16d-f) confirms that the deposition was dominantly under acti- 722 vation control. Thus, the elimination of mass transport limitations in 723 the Ohmic-controlled electrodeposition of metals is due to the ini- 724 tiation of dendritic growth at overpotentials close to that at which 725 complete diffusion control of the process on the flat part of the elec- 726 $\begin{array}{ll}\text { trode surface occurs. } & 727\end{array}$

It is necessary to note that the silver deposits shown in 728 Fig. 16d-f are not similar to ideal silver dendrites, ${ }^{49}$ but they be- 729 have as dendritic ones in regard to their electrochemical properties. 730 Hence, they can be considered as degenerate dendritic deposits. 731

Occasionally, the needle-like dendrites can also be formed. $\quad 732$

On the other hand, due to the overlapping of the nucleation 733 exclusion zones, ${ }^{7,35,36}$ deposition on the partially covered graphite 734 electrode is an excellent illustration of the above discussion. Namely, 735 the diffusion layer on the inert electrode partially covered with grains 736 of active metal can be formed and diffusion control established in the 737 same way as on an electrode of massive active metal if the deposition 738 process is characterized by a large $j_{0} / j_{\mathrm{L}} .{ }^{7}$ If dendrites are formed on 739 the grains, their tips enter the bulk solution and overall control of the 740 deposition process becomes activation or mixed controlled. 741

Naturally, the same effect can be expected if some very fast elec- 742 trochemical process, other than electrodeposition, occurs on the inert 743 electrode partially covered by dendrites of active catalyst, especially 744 if concentration of reacting ion is low. ${ }^{60}$ This could be of great im- 745 portance for the activation of inert substrates for catalytic purposes. 746

It is clear that mass-transfer limitation can be avoided if the de- 747 position process is carried out on dendritic electrodes. In order to 748 illustrate this, the electrode shown in Fig. 17 was used. This is a den- 749 drite electrode. It was obtained by deposition of copper on the tip 750 of a copper wire at an overpotential of $650 \mathrm{mV}$ during $20 \mathrm{~min}$ from 751 $0.15 \mathrm{M} \mathrm{CuSO}_{4}$ in $0.50 \mathrm{M} \mathrm{H}_{2} \mathrm{SO}_{4}$. 
The Effect of Morphology of Activated Electrodes
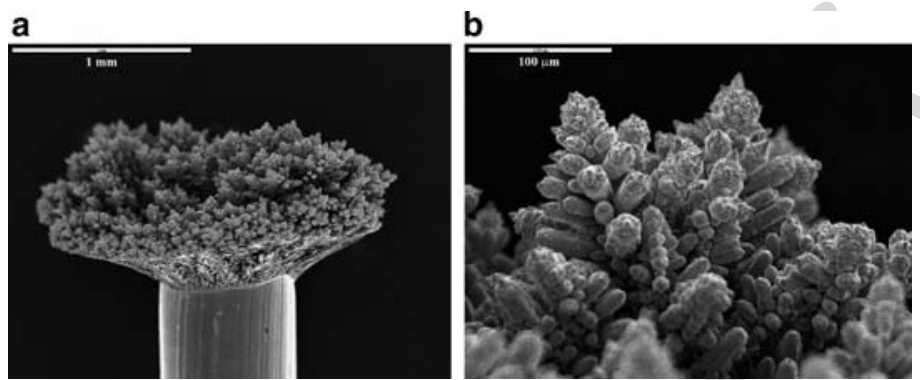

Figure 17. (a) The agglomerate of dendrites obtained by deposition of copper on the tip of a copper wire electrode at $650 \mathrm{mV}$ for $20 \mathrm{~min}$; (b) the outer limit of the dendritic electrode. Reprinted from ref. ${ }^{9}$ with permission from Elsevier.

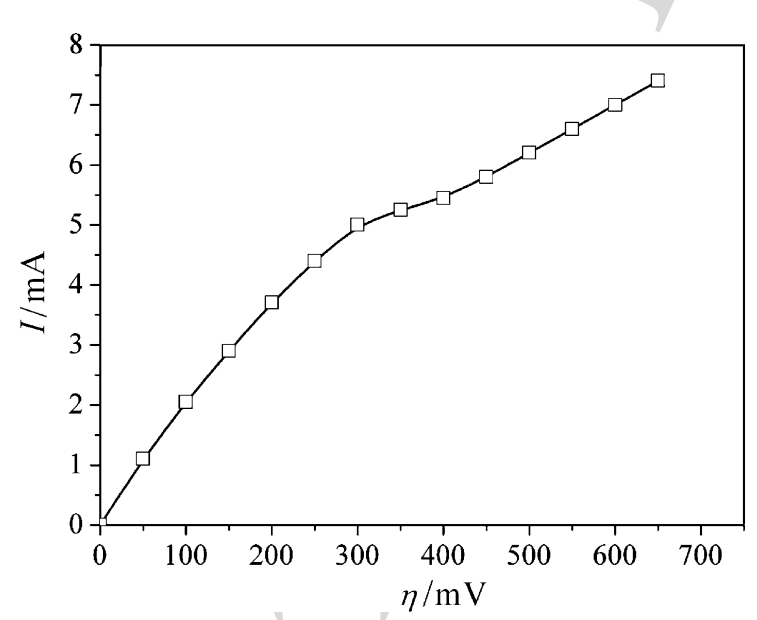

Figure 18. The polarization curve for copper deposition on the electrode from Fig. 17. Reprinted from ref. ${ }^{9}$ with permission from Elsevier.

The polarization curve obtained on it from the same solution is 753 shown in Fig. 18.

The shape of polarization curve in Fig. 18 clearly indicates that 755 after the inflection point, activation control becomes dominant. 756

It also seems that the only way to obtain an ensemble of mi- 757 croelectrodes ${ }^{16}$ working independently under activation control is 758 to form an agglomerate of dendrites, the tips of which represent 759 microelectrodes working in the bulk solution outside any diffusion 760 
K.I. Popov et al.

layer as well as outside the bulk of the agglomerated dendrites. This 761 could be of great importance in the activation of an inert electrode 762 surface by partial covering with dendrites of an active catalyst. $/ 763$

In practice, deposits with high roughness factor and good me- 764 chanical resistance are of particular interest. Dendrites have low me- 765 chanical resistance and they are unsuitable as electrocatalysts, but 766 the elucidation of the Ohmic-controlled electrodeposition of metals 767 due to the dendritic growth is of a great theoretical importance. $\quad 768$

\section{Low Level of Coarseness}

Any solid metal surface that represents a substrate for electrochem- 770 ical reactions possesses a certain roughness. The roughness factor 771 is determined as the ratio of atomic scale real area to the geomet- 772 rically measured apparent one. ${ }^{61}$ In addition, it may appear coarse 773 or smooth, and this is not necessarily related to the roughness. It is 774 the level of coarseness that determines the appearance of the metal 775 surface, while even with considerable roughness, if below the visual 776 level, the surface may appear smooth. It is convenient to define the 777 surface coarseness as the difference in thickness of the metal at the 778 highest and lowest point above a reference plane facing the solution. 779 Figure 19 show cases of surfaces with (a) equal roughness and pro- 780 foundly different coarseness and (b) vice versa. ${ }^{62}$

The apparent surface of polycrystals, measured geometrically, 782 is often two to three times smaller than the real area, because the 783 latter is relatively rough - even if its hills and valleys are invisible 784 to unaided sight. Because various metals and different samples of 785 the same metal may have different roughness factor and because the 786 velocity of an electrode reaction has to be standardized to the real 787 area, the roughness factor has to be determined. ${ }^{61,62}$

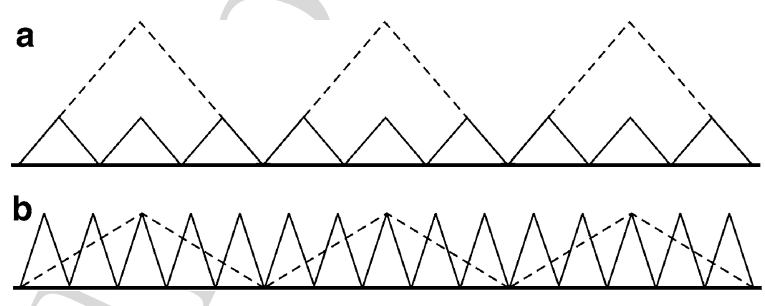

Figure 19. Models of surfaces with: (a) equal surface roughness with different coarseness and (b) vice versa. Reprinted from ref. ${ }^{8}$ with permission of Elsevier. 


\section{The Effect of Morphology of Activated Electrodes}

The standardized values of velocity of electrochemical reac- 789 tions, expressed by the values of exchange current density 790 standardized to real area, can be compared with each other. $/ 791$

Since both the exchange current density and the limiting diffu- 792 sion current density are included in the general cathodic polariza- 793 tion curve equation given by (7), it is necessary to standardize them 794 in the same way, hence, to the apparent surface area. In that case, 795 the exchange current density has some effective value, $j_{0 \text {, eff, given } 796}$ by (68)

$$
j_{0, \mathrm{eff}}=f_{\mathrm{r}} j_{0}
$$

where $f_{\mathrm{r}}$ is the roughness factor and $j_{0}$ is the value of the exchange 798 current density standardized to the ideally smooth electrode surface. 799 In similar way, the $j_{0, \text { eff }}$ was defined earlier for the partially covered 800 inert electrode with active catalyst ${ }^{7}$ and $j$ on porous electrodes. ${ }^{63} \quad 801$

Electrocatalysts are produced in different ways, on different 802 substrates, and for different purposes, ${ }^{10,64-72}$ but almost in all cases 803 the electrochemical characterization was performed by using the 804 cyclic voltammetry observations. In this way, it was not possible 805 to analyze the effects of the mass-transfer limitations on the polar- 806 ization characteristics of electrochemical processes. As shown re- 807 cently, ${ }^{7,9}$ the influence of both kinetic parameters and mass-transfer 808 limitations can be taken into account using the exchange current 809 density to the limiting diffusion current density ratio, $j_{0} / j_{\mathrm{L}}$, for the 810 process under consideration. Increased value of this ratio leads to 811 the decrease of the overpotential at one and the same current density 812 and, hence, to the energy savings.

The basic idea of this section lies in the following facts. In the 814 general polarization curve equation, ${ }^{61}$ both exchange and limiting 815 diffusion current densities are standardized to the apparent electrode 816 surface area. Hence, if the electrode surface roughness is increased, 817 the effective value of exchange current density for process under 818 consideration, standardized to the apparent electrode surface area, is 819 also increased. At the same time, if the level of the electrode sur- 820 face coarseness remains low, the change of the limiting diffusion 821 current density can be neglected. In this way, the value of $j_{0} / j_{\mathrm{L}}$ ratio 822 is increased, what can produce the decrease of overpotential at fixed 823 current density.

At significantly low level of coarseness, the limiting diffu- 825 sion current does not depend on it, being the same as on the flat 826 
electrode surface. On the contrary, even at significantly low level of 827 coarseness, the surface roughness can be considerably increased as 828 well as the value of the effective exchange current density. $\quad 829$

Then, (7) modified with (68) can be used for calculation of the 830 polarization curves for the same electrochemical process at different 831 values of electrode surface roughness at low level of coarseness. $\quad 832$

Using (7) and (68), and $f_{\mathrm{c}}=10^{\eta / 120}$ and $f_{\mathrm{a}}=10^{-\eta / 40}, 833$ $j_{0} / j_{\mathrm{L}}=0.01$ and 0.1 , and $f_{\mathrm{r}}=1,2,5$, and 10 , the dependences 834 presented in Fig. 20 are obtained, being valid for copper electrode- 835 position reaction. The strong decrease of overpotential at the same 836 current densities with increase of the roughness factor of the elec- 837 trode surface can be seen.

The Ohmic drop is not included in the polarization curve from 839 Fig. 20. The dependences of overpotential at fixed current density on 840 $f_{\mathrm{r}}$ are derived from the diagrams in Fig. 20 and presented in Fig. 21. 841 It can be seen from Fig. 21 that the values of overpotential strongly 842 decrease with increase of $f_{\mathrm{r}}$.

There are three possibilities for the increase of both the sur- 844 face roughness and coarseness during electrodeposition of metals. In 845 the activation-controlled electrodeposition the regular crystal grains 846

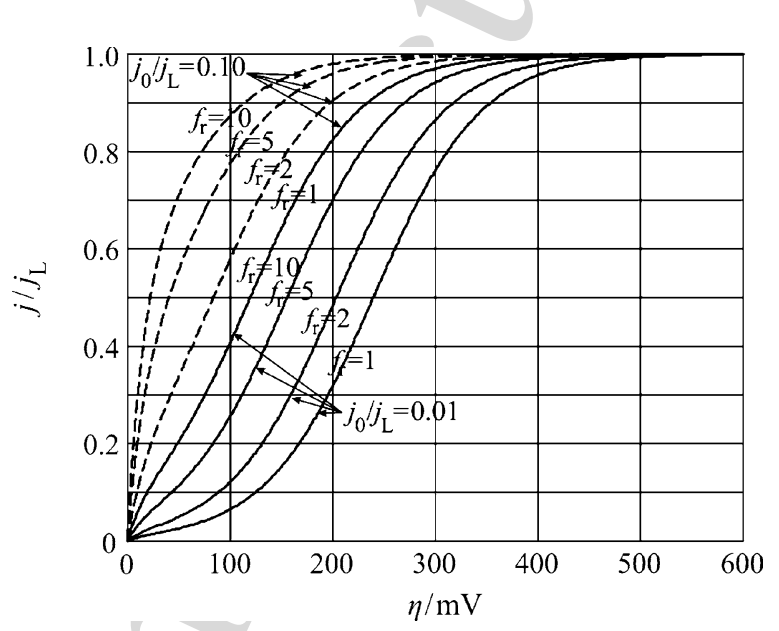

Figure 20. Dependences of $j / j_{\mathrm{L}}-\eta$ calculated from (7) and (68) using $j_{0} / j_{\mathrm{L}}=0.1$ and $0.01, f_{\mathrm{r}}=1,2,5,10$ and $f_{\mathrm{c}}=10^{\eta / 120}$ and $f_{\mathrm{a}}=10^{-\eta / 40}$. Reprinted from ref. ${ }^{8}$ with permission of Elsevier. 
The Effect of Morphology of Activated Electrodes

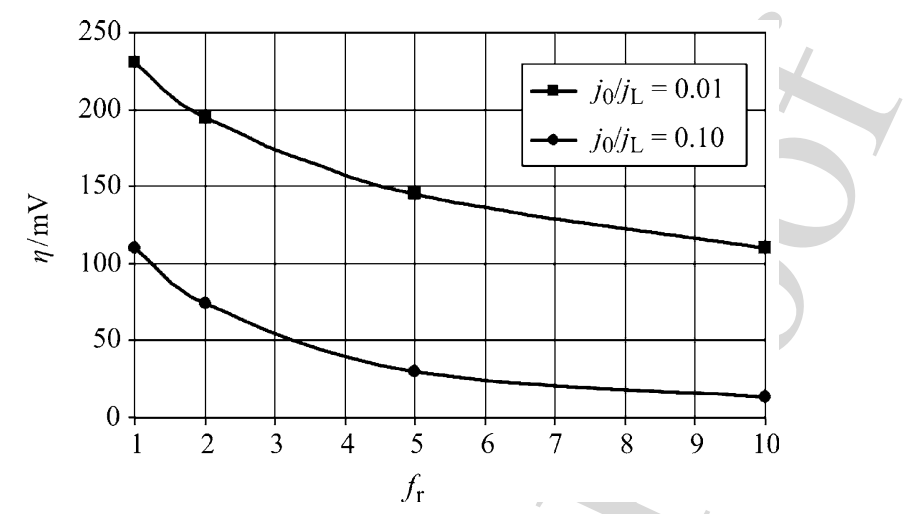

Figure 21. Dependences of overpotential on roughness factor for $j / j_{\mathrm{L}}=0.5$ and different $j_{0} / j_{\mathrm{L}}$ ratios. Data derived from Fig. 20. Reprinted from ref. ${ }^{8}$ with permission of Elsevier.

grow, in the region of mixed activation-diffusion control there is a 847 nondendritic surface coarseness amplifications, and in the complete 848 diffusion control dendritic deposition appears. ${ }^{30,48} \quad 849$

It is obvious that in the first case the situation like that from 850 Fig. 19a can be expected, leading to the increase of surface coarse- 851 ness, i.e., the size of crystal grains, but without considerable change 852 of the surface roughness. In the region of the mixed control, as well 853 as of the diffusion control at overpotentials lower than the overpo- 854 tential required for dendritic growth initiation, the cauliflower-like 855 forms are mainly formed, and they can be approximated by hemi- 856 spherical protrusions. Finally, at overpotentials higher than the one 857 required for dendritic growth initiation, dendrites are formed, and 858 they can be approximated by cones. It is easy to show that for 859 $\delta \gg r$, the surface roughness does not depend on the radius of the 860 cauliflower-like particle. ${ }^{30}$ A schematic presentation of the top view 861 of the flat surface covered with homogeneously distributed equal 862 hemispherical protrusions and corresponding cross section is pre- 863 sented in Fig. 22.

It is easy to show that roughness factor $f_{\mathrm{r}, \mathrm{h}}$ in this case is 865 given as

$$
f_{\mathrm{r}, \mathrm{h}}=1+\frac{\pi}{4}
$$

being independent on the radius of hemispherical protrusions. 

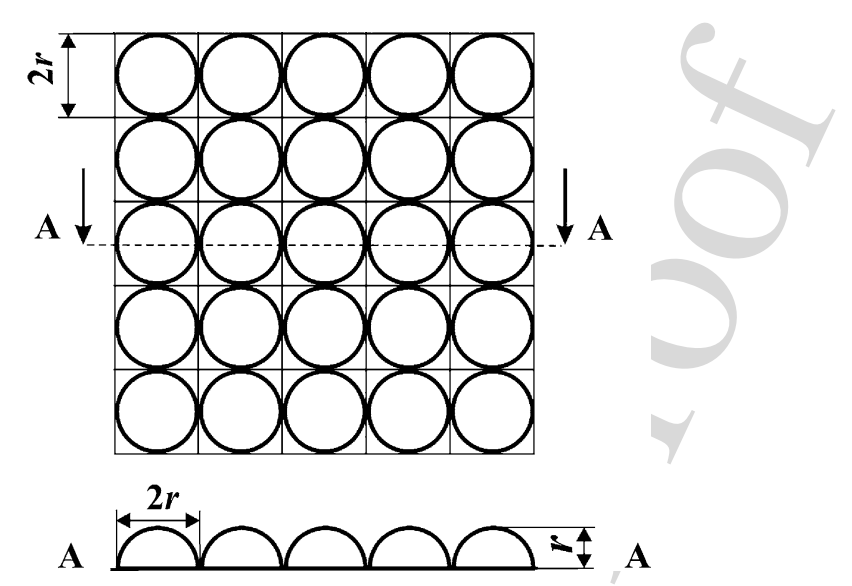

Figure 22. A schematic representation of the top view of the electrode surface modified with equal spherical protrusions and of corresponding cross-section. Reprinted from ref. ${ }^{8}$ with permission of Elsevier.

If instead of hemispherical protrusions, the conic ones are used, 868 characterized by radius of base $r$ and the height $h$, the roughness 869 factor $f_{\mathrm{r}, \mathrm{c}}$ is given as

$$
f_{\mathrm{r}, \mathrm{c}}=1-\frac{\pi}{4}+\frac{\pi}{2 r}\left(h^{2}+r^{2}\right)^{\frac{1}{2}}
$$

being strongly dependant on the $h / r$ ratio. Corresponding schematic 871 presentation is given in Fig. 23.

Although the above illustration is a qualitative one, it can be 873 concluded by the analysis of (69) and (70) that the roughness factor 874 during nondendritic surface roughness amplification can be enlarged 875 about two times. On the other hand, during dendritic growth, ampli- 876 fication can be many times larger than in the nondendritic one. 877

Hence, the activation overpotential can be considerably de- 878 creased by appropriate preparation of electrode surface morphology, 879 especially by formation of disperse deposits at low level of coarse- 880 ness. Obviously, the roughness factor can be increased many times 881 in real situations. It is well known that the surface morphology exerts 882 a marked influence on the electrocatalytic activity of an electrode. ${ }^{73} 883$ At a microscopic level, the existence of pores, crevices, microcav- 884 ities, etc. favors the increase of the electrodic surface area, though 885 
The Effect of Morphology of Activated Electrodes
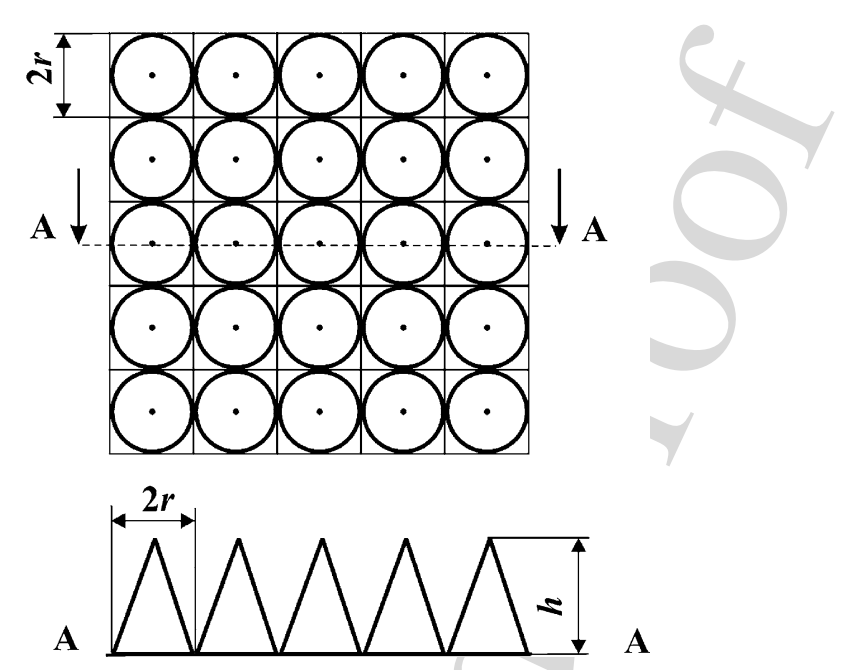

Figure 23. A schematic representation of the top view of the electrode surface modified with equal conical protrusions and of corresponding cross-section. Reprinted from ref. ${ }^{8}$ with permission of Elsevier.

mass transfer, Ohmic, and bubble overvoltages prevent the rates of 886 electrochemical reactions from increasing proportionally. ${ }^{10}$ An ex- 887 ample is the Raney-Nickel electrode used as cathodic material for 888 the hydrogen evolution reaction, for which it has been found that 889 in certain cases only $1.5 \%$ of the available area is used. ${ }^{74}$ In order 890 to avoid the discrepancy between the overall electrode surface and 891 the part of it at which the electrochemical process occurs in pro- 892 longed electrolysis, the procedure of the determination of the effec- 893 tive value of roughness factor has been developed. ${ }^{75}$ This is done by 894 determining the exchange current densities from stationary polar- 895 ization curves. The roughness factors were determined as ratios of 896 the values of exchange current densities on different substrates and 897 on the reference one. In this way, the differences in surface areas 898 taking place in determination of roughness factor and in prolonged 899 electrolysis process are avoided.

The copper deposit obtained by electrodeposition at an over- 901 potential of $300 \mathrm{mV}$ during 2 min at copper cylindrical electrode is 902 shown in Fig. 24a. Copper deposits electrodeposited at overpoten- 903 tials of 550 and $650 \mathrm{mV}$ on the copper electrode presented in Fig. 24a 904 
K.I. Popov et al.

a

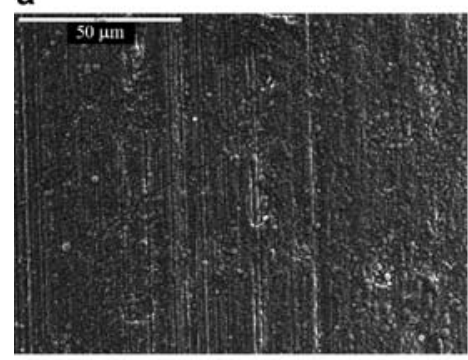

C

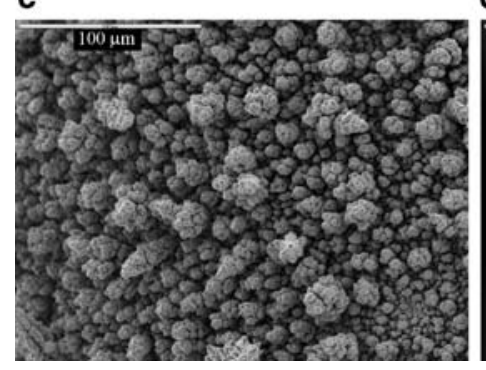

b

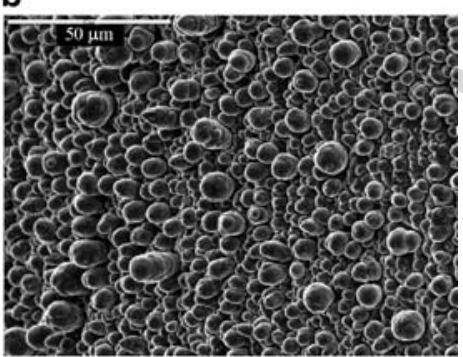

d

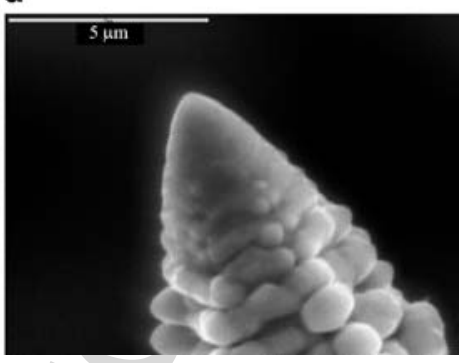

Figure 24. (a) The copper deposit electrodeposited at an overpotential of $300 \mathrm{mV}$ during $2 \mathrm{~min}$ on the cylindrical copper electrode; and copper deposits electrodeposited with $5.0 \mathrm{~mA} \mathrm{~h} \mathrm{~cm}^{-2}$ on the copper substrate from (a) at overpotentials of: (b) $550 \mathrm{mV}$ and (c) $650 \mathrm{mV}$; (d) the top of copper dendrite electrodeposited at an overpotential of $650 \mathrm{mV}$ with a deposition time of $32 \mathrm{~min}$. Reprinted from ref. ${ }^{8}$ with permission of Elsevier.

with a quantity of electricity of $5.0 \mathrm{~mA} \mathrm{~h} \mathrm{~cm}^{-2}$ are shown in Fig. $24 \mathrm{~b} 905$ and c, respectively.

The polarization curves recorded on the cylindrical platinum 907 electrodes treated in the same way as the cylindrical copper elec- 908 trodes in Fig. 24 are shown in Fig. 25. There is not any difference 909 between polarization curves obtained on the copper and platinum 910 substrates.

The mutual position of the polarization curves from Fig. 25912 indicates that the exchange current density corresponding to the sub- 913 strate from Fig. 24c is considerably larger than other ones. The con- 914 clusion can be derived by the comparison of Figs. 20 and 25, because 915 the Ohmic voltage drop in the polarization curves from Fig. 25 does 916 
The Effect of Morphology of Activated Electrodes

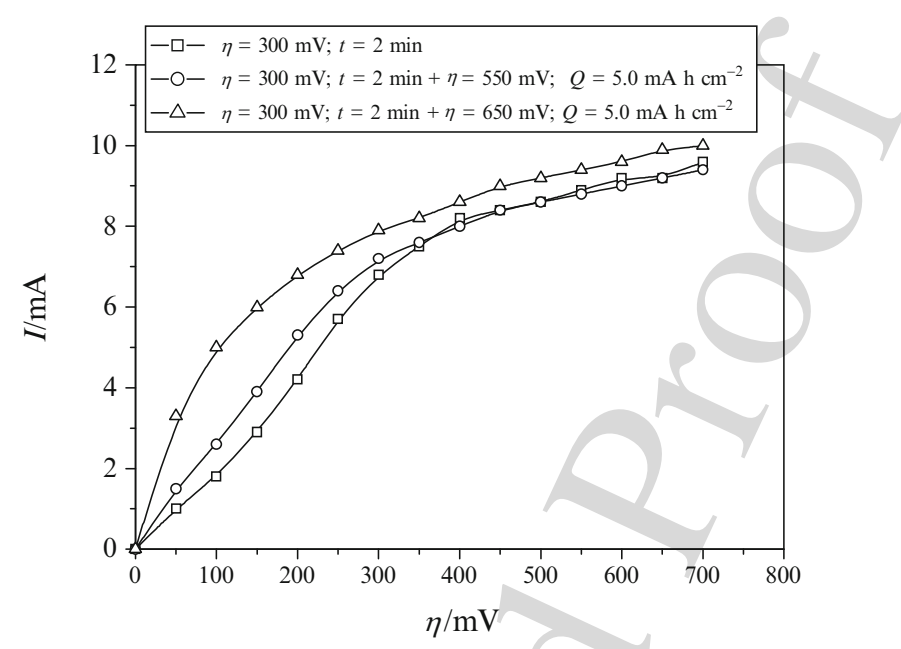

Figure 25. Polarization curves for copper electrodeposition on the cylindrical platinum electrodes treated by copper electrodeposition under the same conditions shown in Fig. $24 \mathrm{a}-\mathrm{c}$. Reprinted from ref. ${ }^{8}$ with permission of Elsevier.

not affect the mutual position of polarization curves in which the 917 Ohmic voltage drop is not included. ${ }^{9}$

On the other hand, as was shown recently, ${ }^{75}$ the value of $j_{0}$ can 919 be estimated using $j_{\mathrm{L}}$ value extracted from the polarization curve 920 and known value of the cathodic Tafel slope $b_{\mathrm{c}}$ by (71)

$$
j_{0}=\frac{j_{\mathrm{L}}}{10^{\frac{\eta_{1 / 2}}{b_{\mathrm{c}}}}}
$$

if the Ohmic voltage drop can be neglected, where $\eta_{1 / 2}$ is the value 922 of overpotential corresponding to the half of limiting diffusion cur- 923 rent density value. For electrode surfaces presented in Fig. 24a-c, 924 using $b_{\mathrm{c}}=120 \mathrm{mV} \mathrm{dec}^{-1}$ and $j_{\mathrm{L}}$ from polarization curves pre- 925 sented in Fig. 25, exchange current density values can be estimated 926 as $j_{0}=0.14,0.27$, and $1.8 \mathrm{~mA} \mathrm{~cm}^{-2}$, respectively. This method can 927 be applied here because the Ohmic voltage drop can be neglected 928 for the electrode whose surface is presented in Fig. 24a. Increasing 929 surface roughness decreases the overpotential at fixed value of ap- 930 parent current density and the contribution of Ohmic voltage drop 931 
to the measured overpotential increases. Because of this, the value 932 of $j_{0}$ calculated by (71) can become lower than the real value, and, 933 hence, it can be used in this qualitative discussion.

Equation (68) can be rewritten in the form

$$
f_{\mathrm{r}}=\frac{j_{0, \mathrm{eff}}}{j_{0}}
$$

Assuming that $j_{0}$ corresponds to the substrate from Fig. 24a and 936 that exchange current density values corresponding to the other sub- 937 strates are the effective values, roughness factors of 1.9 and 13 for 938 substrates shown in Fig. 24b, c, respectively, are obtained. The cop- 939 per deposit formed by the nondendritic surface coarseness ampli- 940 fication at an overpotential of $550 \mathrm{mV}$ (Fig. 24b) is well described 941 by Fig. 22, and calculated value of 1.9 is close to the one predicted 942 by (69). The copper deposit obtained at an overpotential of $650 \mathrm{mV} 943$ (Fig. 24c) represents the precursors of dendrites which can be de- 944 scribed, more or less successfully, by cones from Fig. 23. It is nec- 945 essary to note that different forms on such surface are formed, from 946 the dendritic precursor to completely formed dendrite. Also, it can 947 be clearly seen from Fig. 24d that the top of the dendrite formed at an 948 overpotential of $650 \mathrm{mV}$ was like a cone. Anyway, inhomogeneous 949 surface with different levels of coarseness was obtained, regardless 950 of the limiting diffusion current density value, which was not consid- 951 erably increased. The roughness factor for this electrode, calculated 952 by $(72)$, is $f_{\mathrm{r}}=13$, being considerably larger than the previous one. 953

The formation of the smaller (and less different to each other) 954 dendrites could be obtained by the increase of deposition over- 955 potential. Unfortunately, the increased overpotential produces the 956 hydrogen evolution in this system and the formation of degenerate 957 dendrites and honeycomb-like deposits. ${ }^{76,77}$ Nevertheless, the den- 958 dritic growth in this system at larger overpotentials is possible by the 959 application of appropriate square-wave pulsating overpotential (PO) 960 regime. For example, the well-developed dendrites were formed with 961 amplitude overpotential of $1,000 \mathrm{mV}$, deposition pulse of $10 \mathrm{~ms}$, and 962 pause of $100 \mathrm{~ms}$ (the pause to pulse ratio: 10) (Fig. 26a). They can be 963 well approximated by the cones shown in Fig. 23. Also, superficial 964 holes due to attached hydrogen bubbles were formed between these 965 dendrites, as can be seen from ref. ${ }^{78}$

The precursors of dendrites, like a cone, were also formed by 967 the square-wave PO with the same amplitude overpotential and the 968 


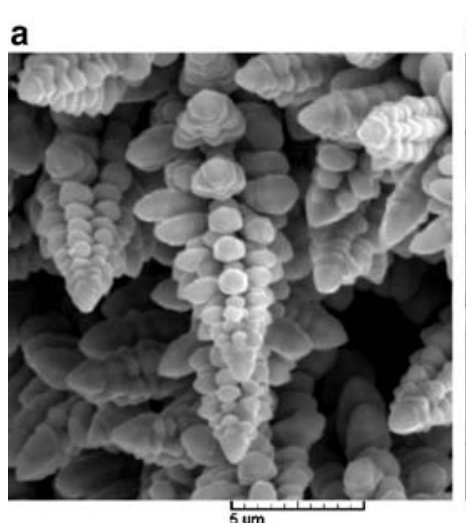

$5 \mathrm{um}$

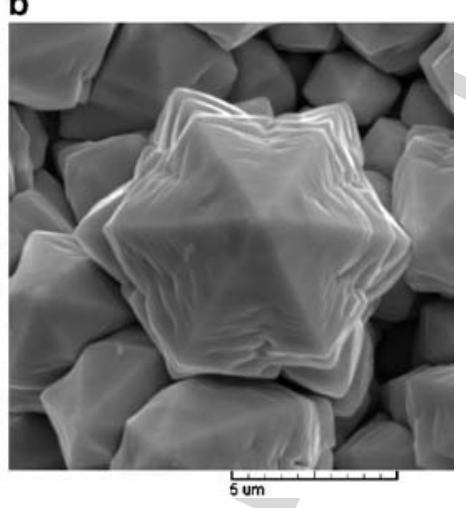

Figure 26. (a) The copper dendrites formed by the pulsating overpotential (PO) regime: deposition pulse of $10 \mathrm{~ms}$, pause duration of $100 \mathrm{~ms}$; deposition time: $18 \mathrm{~min}$; (b) The precursor of copper dendrite obtained by PO regime: deposition pulse of $1 \mathrm{~ms}$, pause duration of $10 \mathrm{~ms}$; deposition time: $24 \mathrm{~min}$. In both cases amplitude overpotential used was $1,000 \mathrm{mV}$. Reprinted from ref. ${ }^{8}$ with permission of Elsevier.

pause to pulse ratio of 10, but by applying deposition pulse of $1 \mathrm{~ms} 969$ and pause of $10 \mathrm{~ms}$ (Fig. 26b). In this square-wave PO, hydrogen 970 evolution was avoided. ${ }^{79}$

The polarization curves for copper deposition on the elec- 972 trodes whose surfaces are shown in Fig. 24a and 26a are given 973 in Fig. 27. It is obvious that the noticeable increase of the ex- 974 change current density attained by the application of the PO regime 975 $\left(j_{0, \text { eff }}=3.3 \mathrm{~mA} \mathrm{~cm}^{-2} ; f_{\mathrm{r}}=23.5\right)$ is followed by the minimal 976 increase of limiting diffusion current density, relative to the one 977 corresponding to the substrate from Fig. 24a.

The same polarization characteristics exhibit the platinum elec- 979 trode modified with copper dendrites formed by the use of the PO 980 regime described in caption of Fig. 26a. It can be seen from Fig. 27981 that the process on the electrode with increased surface rough- 982 ness takes place at considerably lower overpotential than on the 983 smoother one. 
K.I. Popov et al.

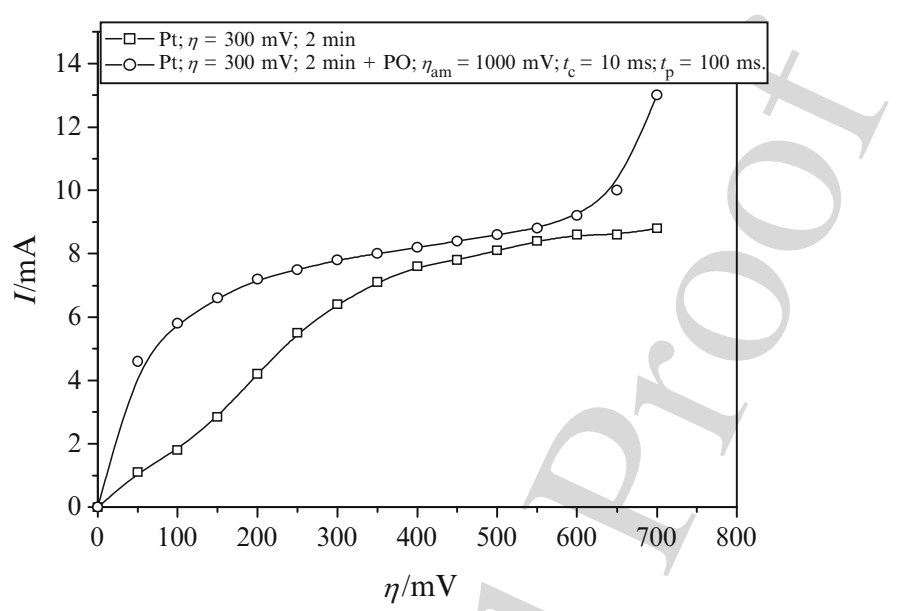

Figure 27. Polarization curves for copper electrodeposition on the substrates from Figs. 24a and 26a. Reprinted from ref. ${ }^{8}$ with permission of Elsevier.

\section{APPLIED ASPECTS}

The discussion presented in this chapter is new, and it is difficult 986 to relate it to some current applications. However, some impor- 987 tant conclusions and recommendations can be suggested from this 988 chapter.

989

First, it is possible to produce the copper dendrites by the PO 990 deposition at the overpotential amplitude at which in a constant cur- 991 rent regime the honeycomb-like deposits are formed. The dendrites 992 produced by the PO regime were very small but well developed, in- 993 creasing considerably the electrode surface roughness even at low 994 level of coarseness. In other words, the apparent exchange current 995 density of the electrochemical process occurring on such electrode 996 can be increased for more than 20 times in comparison with one 997 occurring at the smooth electrode surface. This result suggests that 998 important saving in energy can be achieved. A nondendritic surface 999 roughening does not produce significant increase in the exchange 1000 current density.

Second, as it was recently shown, ${ }^{2,9}$ the ratio of the exchange 1002 current density and the limiting diffusion current density, $j_{0} / j_{\mathrm{L}}, 1003$ determines the polarization characteristics of an electrochemical 1004 processes. Increased value of this ratio leads to a decrease of the 1005 


\section{The Effect of Morphology of Activated Electrodes}

activation overpotential at the same applied current density. If 1006 $j_{0} / j_{\mathrm{L}} \geq 100$, the process becomes Ohmic controlled. In this sit- 1007 uation, not only the activation overpotential is lost, but also the 1008 diffusion overpotential at current densities lower than the limiting 1009 diffusion is lost. This means that the electrochemical process on the 1010 smooth electrode surface characterized by the value of $j_{0} / j_{\mathrm{L}}<51011$ can be transformed to Ohmic-controlled one on the electrode surface 1012 from Fig. 26a.

As already shown, for selected set of operating conditions, the 1014 $j_{0, \text { eff }} / j_{\mathrm{L}}$ value can be only altered by a change of the electrode sur- 1015 face roughness. The $j_{0} / j_{\mathrm{L}}$ ratio for the electrode whose surface is 1016 presented in Fig. 24a is 0.018 and for that presented in Fig. 26a is 1017 0.40. It can be seen from Fig. 27 that at same current densities, be- 1018 longing to the operating region of current density, about $70 \%$ of 1019 overpotential, hence energy, can be saved by using electrode with 1020 larger surface roughness at approximately the same surface coarse- 1021 ness. As explained earlier, the Ohmic voltage drop is neglected in 1022 this case.

Copper shows a high activity for nitrate ion reduction ${ }^{80,81}$ as 1024 well as for a reaction in which nitrate is reduced to ammonia with 1025 a high yield from aqueous acidic perchlorate and sulphate solu- 1026 tions. ${ }^{82}$ In the future, the comparison of the polarization character- 1027 istics of the mentioned reactions on a smooth electrode surface and 1028 on the rough one at low level of coarseness should be investigated in 1029 detail.

The electrode surface roughness at low level of coarseness can 1031 be increased in some different ways other than dendrites (spongy- 1032 like deposit, ${ }^{33}$ honeycomb-like structure, ${ }^{76,77}$ pyramid-like de- 1033 posit, ${ }^{83}$ etc.) on the microscale. The properties of electrodeposits on 1034 nanoscale should be also taken into consideration. ${ }^{84,85}$ Further in- 1035 vestigation will show which one of them is the best for this purpose. 1036 This chapter is written in order to initiate it.

\section{CONCLUSIONS}

A completely new approach to the analysis of experimental data is 1039 introduced by the use of the complete polarization curve equation 1040 and by the method of digital simulation. It was possible in this way 1041 to elucidate the polarization behavior of the partially covered inert 
electrodes, the essence of the Ohmic-controlled electrodeposition of 1042 metals, and the electrocatalytic properties of disperse electrodeposits 1043 formed at low level of the electrode coarseness. $\quad 1044$

Doubtless, the main contribution of this chapter is (57), which 1045 correlates the quantity of catalyst required for complete activa- 1046 tion of inert electrode with size and density of hemispherical ac- 1047 tive grain and parameters of electrochemical process taking place 1048 on them.

The work was supported by the Ministry of Science and Technolog- 1051 ical Development of the Republic of Serbia under the research 1052 projects: "Deposition of ultrafine powders of metals and al- 1053 loys and nanostructured surfaces by electrochemical techniques" 1054 (No. 142032G) and "Modification of metal and nonmetal materials 1055 by electroconductive polymer for application in new technologies" 1056 (No. 142044).

\section{REFERENCES}

${ }^{1}$ S. Trasatti, "Electrocatalysis in Water Electrolysis", Book of Abstracts, 1st Regional 1059 Symposium on Electrochemistry of South-East Europe, Rovinj, Croatia (2008) 1. 1060

${ }^{2}$ Y. Takasu, T. Kawaguchi, W. Sugimoto, and Y. Murakami, Electrochim. Acta 481061

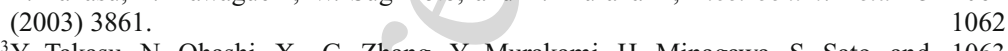

${ }^{3}$ Y. Takasu, N. Ohashi, X. -G. Zhang, Y. Murakami, H. Minagawa, S. Sato, and 1063 K. Yahikozawa, Electrochim. Acta 41 (1996) 2595. ${ }^{4}$ N. Pron'kin, O. A. Petrii, G. A. Tsirlina, and D. J. Schiffrin, J. Electroanal. Chem. 1065 480 (2000) 112. 1066

${ }^{5}$ L. Nzoghe-Mendome, A. Aloufy, J. Ebothe, M. El Messiry, and D. Hui, J. Cryst. 1067 Growth 311 (2009) 1206. 1068

${ }^{6}$ J. O’M. Bockris, A. K. N. Reddy, and M. Gamboa-Aldeco, Modern Electrochem- 1069 istry 2 A, 2nd edition, Kluwer/Plenum, New York (2000) 1361. 1070

${ }^{7}$ K. I. Popov, P. M. Živković, and B. N. Grgur, Electrochim. Acta 52 (2007) 4696. 1071

AQ6 ${ }^{8}$ K. I. Popov, N. D. Nikolić, P. M. Živković, and G. Branković, Electrochim. Acta, in 1072

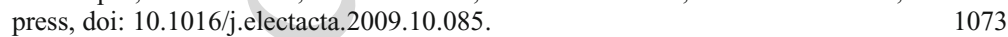

${ }_{9}^{9}$ K. I. Popov, P. M. Živković, S. B. Krstić, and N. D. Nikolić, Electrochim. Acta 541074 $\begin{array}{ll}\text { (2009) } 2924 . & 1075\end{array}$

${ }^{10}$ C. A. Marozzi and A. C. Chialvo, Electrochim. Acta 45 (2000) 2111.

${ }^{11}$ J. L. Barton and J. O'M. Bockris, Proc. R. Soc. A 268 (1962) 485.

${ }^{12}$ J. W. Diggle, A. R. Despić, and J. O’M Bockris, J. Electrochem. Soc. 116 (1969) 1078 1503. 


\section{The Effect of Morphology of Activated Electrodes}

${ }^{13}$ A. R. Despić, J. W. Diggle, and J. O’M Bockris, J. Electrochem. Soc. 116 (1969) 1080 $507 . \quad 1081$

${ }^{14}$ J. O'M. Bockris and A. K. N. Reddy, Modern Electrochemistry 2 B, 2nd edition, 1082 Kluwer/Plenum, New York (2000) $1811 . \quad 1083$

${ }^{15}$ B. Scharifker and G. Hills, Electrochim. Acta 28 (1983) 879.

${ }^{16}$ E. Gilleadi, Electrode Kinetics, VCH Publishers, New York (1993) 443.

${ }^{17}$ P. Stonehart and D. Wheeler, "Phosphoric Acid Fuel Cells (PAFCs) for vehicles; 1086 Electrocatalyst Crystalite Design, Carbon Support, and Matrix Materials Chal- 1087 lenges" in Modern Aspects of Electrochemistry, Vol. 38, Ed. by B. E. Conway, 1088 Kluwer/Plenum, New York (2005) Chapter 4, 385. 1089

${ }^{18}$ J. O'M. Bockris, A. K. N. Reddy, and M. Gamboa-Aldeco, Modern Electrochem- 1090 istry 2 A, 2nd edition, Kluwer/Plenum, New York (2000) 1248. 1091

${ }^{19}$ K. I. Popov, S. S. Djokić, and B.N. Grgur, Fundamental Aspects of Electrometal- 1092 lurgy, Kluwer/Plenum, New York (2002) Chapter 3, 14. 1093

${ }^{20}$ K. I. Popov, N. V. Krstajić, and M. I. Čekerevac, "The Mechanism of Formation of 1094 Coarse and Disperse Electrodeposits" in Ed. by R. E. White, B. E. Conway, and 1095 J. O’M. Bockris, Modern Aspects of Electrochemistry, Vol. 30, Plenum, New York 1096 (1996) Chapter 3, $262 . \quad 1097$

${ }^{21}$ K. I. Popov, M. D. Maksimović, J. D. Trnjavčev, and M. G. Pavlović, J. Appl. Elec- 1098 trochem. 11 (1981) 239.

${ }^{22}$ J. S. Newman, Electrochemical Systems, Prentice-Hall, Engelwood Cliffs, NJ 1100 (1973) $177 . \quad 1101$

${ }^{23}$ M. N. Dešić, M. M. Popović, M. D. Obradović, Lj. M. Vračar, and B. N. Grgur, 1102

J. Serb. Chem. Soc. 70 (2005) 231. 1103

${ }^{24}$ P. M. Živković, B. N. Grgur, and K. I. Popov, J. Serb. Chem. Soc. 73 (2008) 227. 1104

${ }^{25}$ J. O’M. Bockris, A. K. N. Reddy, and M. Gamboa-Aldeco, Modern Electrochem- 1105

istry 2 A, 2nd edition, Kluwer/Plenum, New York (2000) 1107.

${ }^{26}$ K. I. Popov, S. S. Djokić, and B.N. Grgur, Fundamental Aspects of Electrometal- 1107 lurgy, Kluwer/Plenum, New York (2002) Chapter 3, 87, 88. 1108

${ }^{27}$ P. B. Price and D. A. Vermilyea, J. Chem. Phys. 28 (1958) 720.

${ }^{28}$ W. Lorenz, Z. Electrochem. 58 (1954) 912. 1110

${ }^{29}$ B. E. Mattsson and J. O’M. Bockris, Trans. Faraday Soc. 55 (1959) 1586.

${ }^{30}$ K. I. Popov, S. S. Djoki, and B.N. Grgur, Fundamental Aspects of Electrometallurgy, 1112 Kluwer/Plenum, New York (2002) Chapter 3, 56. 1113

${ }^{31}$ K. I. Popov, V. Radmilović, B. N. Grgur, and M. G. Pavlović, J. Serb. Chem. Soc. 591114 $\begin{array}{ll}\text { (1994) } 47 . & 1115\end{array}$

${ }^{32}$ K. I. Popov, N. V. Krstajić, S. R. Popov, and M. I. Čekerevac, J. Appl. Electrochem. 1116 16 (1986) 771. 1117

${ }^{33}$ K. I. Popov and N. V. Krstajić, J. Appl. Electrochem. 13 (1983) 775.

${ }^{34}$ K. I. Popov, N. V. Krstajić, and S. R. Popov, J. Appl. Electrochem. 15 (1985) 151.1119

${ }^{35}$ I. Markov, A. Boynov, and S. Toshev, Electrochim. Acta 18 (1973) 377.

${ }^{36}$ S. Štrbac, Z. Rakočević, K. I. Popov, M. G. Pavlović, and R. Petrović, J. Serb. Chem. 1121

Soc. 64 (1999) $483 . \quad 1122$

${ }^{37}$ A. Dimitrov, S. Hadži-Jordanov, K. I. Popov, and M. G. Pavlović, J. Appl. Elec- 1123

trochem. 28 (1998) 791. 1124

${ }^{38}$ V. Radmilović, K. I. Popov, M. G. Pavlović, A. Dimitrov, and S. Hadži-Jordanov, 1125

J. Solid State Electrochem. 2 (1998) 162.

${ }^{39}$ K. I. Popov, B. N. Grgur, E. R. Stoiljković, M. G. Pavlović, and N. D. Nikolić, J. Serb. 1127

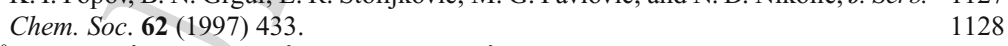

${ }^{40}$ G. D. Adžić, A. R. Despić, and D. M. Dražić, J. Electroanal. Chem. 220 (1988) 169. 1129

${ }^{41}$ G. D. Adžić, A. R. Despić, and D. M. Dražić, J. Electroanal. Chem. 241 (1988) 353. 1130 
K.I. Popov et al.

${ }^{42}$ N. Ya. Kovarskii and T. A. Arzhanova, Elektrokhimiya 22 (1986) 452. 1131

${ }^{43}$ M. L. Avramov Ivić, S. D. Petrović, P. M. Živković, N. D. Nikolić, and K. I. Popov, 1132

J. Electroanal. Chem. 549 (2003) $129 . \quad 1133$

${ }^{44}$ K. I. Popov, M. G. Pavlović, Lj. J. Pavlović, M. I. Čekerevac, and G. Ž. Remović, 1134

Surf. Coat. Technol. 34 (1988) 355.

${ }^{45}$ K. I. Popov, N. V. Krstajić, Z. D. Jerotijević, and S. P. Marinković, Surf. Technol. 261136

(1985) $185 . \quad 1137$

${ }^{46}$ K. J. Vetter, Electrochemical kinetics, Khimiya, Moskva, 1967, p. 699, 1138

Section 162 C, and references therein (in Russian). 1139

${ }^{47}$ K. I. Popov, N. V. Krstajić, and S. R. Popov, Surf. Technol. 20 (1983) 203.

${ }^{48}$ K. I. Popov, S. S. Djokić, and B.N. Grgur, Fundamental Aspects of Electrometal- 1141

lurgy, Kluwer/Plenum, New York (2002) Chapter 3, 78. 1142

${ }^{49}$ G. Wranglen, Electrochim. Acta 2 (1960) 130.

${ }^{50}$ A. R. Despić and K. I. Popov, "Transport controlled Deposition and Dissolution of 1144

Metals", in Ed. by B. E. Conway and J. O'M. Bockris, Modern Aspects of Electro- 1145

chemistry, Vol. 7, Plenum, New York (1972) Chapter 4, 241.

${ }^{51}$ I. N. Justinijanović and A. R. Despić, Electrochim. Acta 18 (1973) 709.

${ }^{52}$ K. I. Popov, M. I. Čekerevac, and Lj. M. Nikolić, Surf. Coat. Technol. 34 (1988) 219. 1148

${ }^{53}$ K. I. Popov and M. I. Čekerevac, Surf. Coat. Technol. 37 (1989) 435.

${ }^{54}$ I. M. Epstein, Elektrokhimiya 2 (1966) 734.

${ }^{55}$ K. I. Popov, N. V. Krstajić, and M. I. Čekerevac, "The Mechanism of Formation of 1151 Coarse and Disperse Electrodeposits" in Ed. by R. E. White, B. E. Conway, and 1152 J. O’M. Bockris, Modern Aspects of Electrochemistry, Vol. 30, Plenum, New York 1153 (1996) Chapter 3, $294 . \quad 1154$

${ }^{56}$ K. I. Popov, N. V. Krstajić, and M. I. Čekerevac, "The Mechanism of Formation of 1155 Coarse and Disperse Electrodeposits" in Ed. by R. E. White, B. E. Conway, and 1156 J. O’M. Bockris, Modern Aspects of Electrochemistry, Vol. 30, Plenum, New York 1157 (1996) Chapter 3, $308 . \quad 1158$ ${ }^{57}$ S. Meibhur, E. Yeager, A. Kozawa, and F. Hovorka, J. Electrochem. Soc. 110 (1963) 1159 $190 . \quad 1160$

${ }^{58}$ K. I. Popov, M. G. Pavlović, E. R. Stojilković, and Z. Ž. Stevanović, Hydrometal- 1161 lurgy 46 (1997) $321 . \quad 1162$

${ }^{59}$ N. Ibl and K. Schadegg, J. Electrochem. Soc. 114 (1967) $54 . \quad 1163$

${ }^{60}$ P. M. Živković, N. D. Nikolić, M. Gvozdenović, and K. I. Popov, J. Serb. Chem. Soc. 1164

74 (2009) 291. 1165

${ }^{61}$ J. O’M. Bockris, A. K. N. Reddy, and M. Gamboa-Aldeco, Modern Electrochem- 1166 istry 2 A, 2nd edition, Kluwer/Plenum, New York (2000) 1095.

${ }^{62}$ A. R. Despić and K. I. Popov, "Transport controlled Deposition and Dissolution of 1168 Metals", in Ed. by B. E. Conway and J. O'M. Bockris, Modern Aspects of Electro- 1169 chemistry, Vol. 7, Plenum, New York (1972) Chapter 4, 204.

${ }^{63}$ Yu. Chizmadzhev and Yu. G. Chirkov, "Porous Electrodes", in Ed. by E. Yeager, 1171 J. O’M. Bockris, B. E. Conway, and S. Sarangapani, Comprehensive Treatise of 1172 Electrochemistry, Vol. 6, Plenum, New York and London (1983) Chapter, 317. 1173

${ }^{64}$ M. V. Ananth, V. V. Giridhar, and K. Renuga, Int. J. Hydrogen Energ. 34 (2009) 658. 1174

${ }^{65}$ C. A. Marozzi and A. C. Chialvo, Electrochim. Acta 46 (2001) 861. 1175

${ }^{66}$ L. Zhou, Y. F. Cheng, and M. Amrein, J. Power Sources 177 (2008) 50.

${ }^{67}$ M. Imamura, T. Haruyama, E. Kobatake, Y. Ikariyama, and M. Aizawa, Sens. Actu- 1177 ators B 24-25 (1995) 113. 1178

${ }^{68}$ H. -K. Seo, D. -J. Park, and J. -Y. Park, Thin Solid Films 516 (2008) 5227.

${ }^{69}$ I. G. Casella, Electrochim. Acta 54 (2009) 3866. 


\section{Author's Proof}

BookID 186658_ChapID 4_Proof\# 1 - 17/02/10

The Effect of Morphology of Activated Electrodes

${ }^{70}$ S. A. S. Machado, J. Tiengo, P. de Lima Neto, and L. A. Avaca, Electrochim. Acta 1181 39 (1994) $1757 . \quad 1182$

${ }^{71}$ L. Li, F. Ye, L. Chen, T. Wang, J. Li, and Z. Wang, J. Power Sources 186 (2009) 320. 1183

${ }^{72}$ V. Diaz, S. Real, E. Teliz, C. F. Zinola, and M. E. Martins, Int. J. Hydrogen Energ. 1184 34 (2009) 3519.

${ }^{73}$ D. Pletcher, J. Appl. Electrochem. 14 (1984) 403.

1185

${ }^{7}$ K. Lohrberg and P. Kohl, Electrochim. Acta 29 (1984) 1557.

${ }^{75}$ N. D. Nikolić, Lj. J. Pavlović, M. G. Pavlović, and K. I. Popov, J. Serb. Chem. Soc. 1188

72 (2007) 1369. 1189

${ }^{76}$ N. D. Nikolić, K. I. Popov, Lj. J. Pavlović, and M. G. Pavlović, J. Electroanal. Chem. 1190

588 (2006) 88. 1191

${ }^{77}$ N. D. Nikolić, Lj. J. Pavlović, M. G. Pavlović, and K. I. Popov, Electrochim. Acta 521192 (2007) 8096. 1193

${ }^{78}$ N. D. Nikolić, G. Branković, V. M. Maksimović, M. G. Pavlović, and K. I. Popov, 1194 J. Solid State Electrochem. 14 (2010) 331.

${ }^{79}$ N. D. Nikolić, G. Branković, V. M. Maksimović, M. G. Pavlović, and K. I. Popov, 1196

J. Electroanal. Chem. 635 (2009) $111 . \quad 1197$

${ }^{80}$ G. E. Dima, A. C. A. de Vooys, and M. T. M. Koper, J. Electroanal. Chem. 554-555 1198

(2003) $15 . \quad 1199$

${ }^{81}$ W. -Y. Ko, W. -H. Chen, C. -Y. Cheng, and K. -J. Lin, Sens. Actuators B 1371200

(2009) $437 . \quad 1201$

${ }^{82}$ D. Pletcher and Z. Poorbedi, Electrochim. Acta 24 (1979) 1253.

${ }^{83}$ K. I. Popov, T. M. Kostić, N. D. Nikolić, E. R. Stojilković, and M. G. Pavlović, 1203

\begin{tabular}{ll} 
J. Electroanal. Chem. 464 (1999) 245. & 1204 \\
\hline
\end{tabular}

${ }^{84}$ A. J. Arvia and R. C. Salvarezza, Electrochim. Acta 39 (1994) 1481.

${ }^{85}$ W. -Y. Ko, W. -H. Chen, S. -D. Tzeng, S. Gwo, and K. -J. Lin, Chem. Mater. 181206 (2006) 6097. 